FEDERAL RESERVE BANK OF SAN FRANCISCO

WORKING PAPER SERIES

\title{
Country Spreads and Emerging Countries: Who Drives Whom?
}

\author{
Martin Uribe \\ Duke University and NBER \\ and \\ Vivian Z. Yue \\ University of Pennsylvania
}

Working Paper 2004-32

http:/www.frbsf.org/publications/economics/papers/2004/wp04-32bk.pdf

This paper was presented at the conference on "Emerging Markets and Macroeconomic Volatility: Lessons from a Decade of Financial Debacles" cosponsored by the Center for Pacific Basin Studies of the Federal Reserve Bank of San Francisco and the Center for International Economics at the University of Maryland and held at the FRBSF on June 4-5 2004. The views in this paper are solely the responsibility of the authors and should not be interpreted as reflecting the views of the Federal Reserve Bank of San Francisco or the Board of Governors of the Federal Reserve System 


\title{
Country Spreads and Emerging Countries: Who Drives Whom?*
}

\author{
Martín Uribe ${ }^{\dagger}$ \\ Duke University and NBER \\ Vivian Z. Yue \\ University of Pennsylvania
}

First Draft: July 28, 2003

This draft: October 8, 2003

\begin{abstract}
A number of studies have stressed the role of movements in US interest rates and country spreads in driving business cycles in emerging market economies. At the same time, country spreads have been found to respond to changes in both the US interest rate and domestic conditions in emerging markets. These intricate interrelationships leave open a number of fundamental questions: Do country spreads drive business cycles in emerging countries or vice versa, or both? Do US interest rates affect emerging countries directly or primarily through their effect on country spreads? This paper addresses these and other related questions using a methodology that combines empirical and theoretical elements. The main findings are: (1) US interest rate shocks explain about 20 percent of movements in aggregate activity in emerging market economies at business-cycle frequency. (2) Country spread shocks explain about 12 percent of business-cycle movements in emerging economies. (3) About 60 percent of movements in country spreads are explained by country-spread shocks. (4) In response to an increase in US interest rates, country spreads first fall and then display a large, delayed overshooting; (5) US-interest-rate shocks affect domestic variables mostly through their effects on country spreads. (6) The fact that country spreads respond to business conditions in emerging economies significantly exacerbates aggregate volatility in these countries. (7) The US-interest-rate shocks and country-spread shocks identified in this paper are plausible in the sense that they imply similar business cycles in the context of an empirical VAR model as they do in the context of a theoretical dynamic general equilibrium model of an emerging market economy.
\end{abstract}

JEL Classification: F41, G15.

${ }^{*}$ We are grateful to Stephanie Schmitt-Grohé, Luis Palacios, Andy Neumeyer, Tony Richards, and Barbara Rossi for comments and discussions; and to seminar participants at Duke University, the University of Montreal, the Federal Reserve Bank of Richmond, Colegio de Mexico, Banco de Mexico, and the ITAMFBBVA Summer Camp in Macroeconomics (Mexico City, August 13-15, 2003). Yue gratefully acknowledges financial support from the Weiss Center at the Wharton School, University of Pennsylvania.

†E-mail: uribe@econ.duke.edu.

${ }^{\ddagger}$ E-mail: yuez@econ.upenn.edu. 
Keywords: Country Risk Premium, Business Cycles, Small Open Economy. 


\section{Introduction}

Business cycles in emerging market economies are correlated with the cost of borrowing that these countries face in international financial markets. This observation is illustrated in figure 1, which depicts detrended output and the country interest rate for seven developing

Figure 1: Country Interest Rates and Output in Seven Emerging Countries
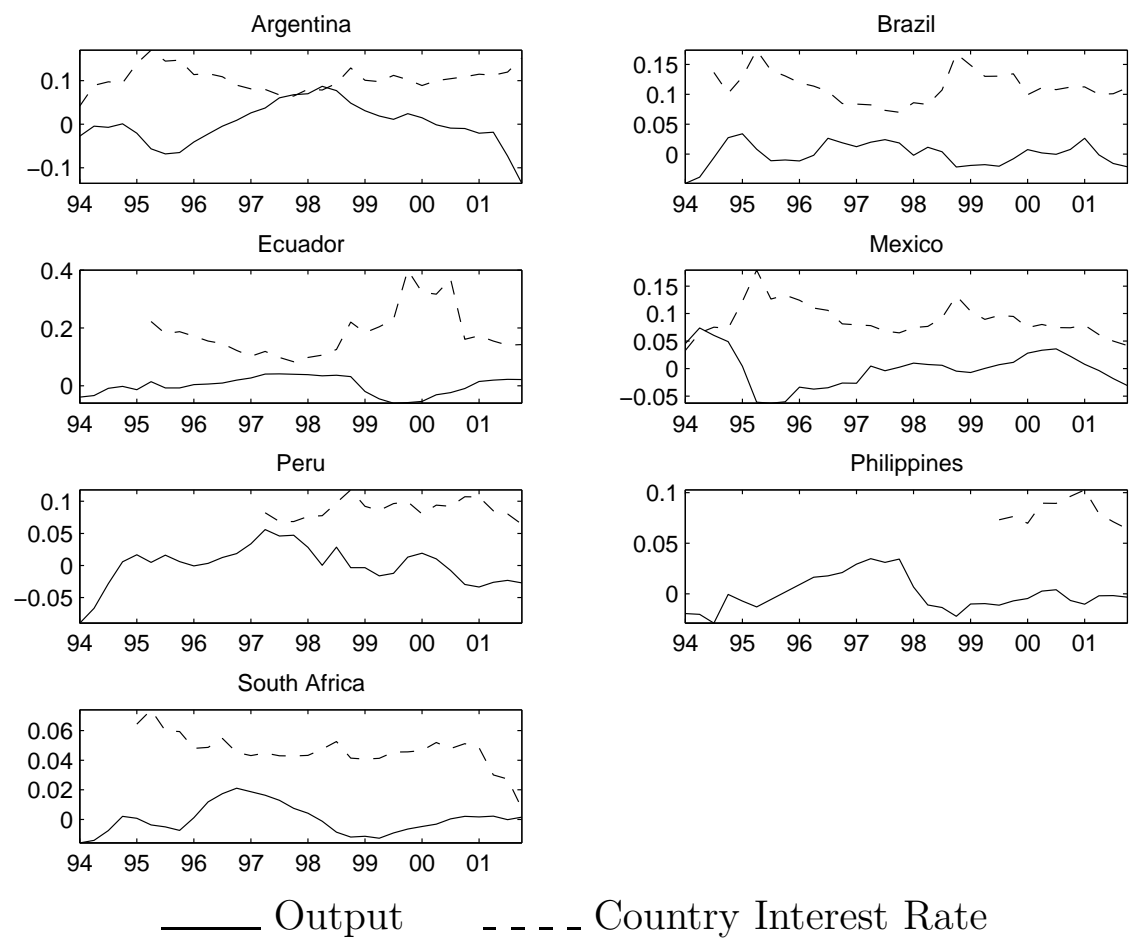

Note: Output is seasonally adjusted and detrended using a log-linear trend. Country interest rates are real yields on dollar-denominated bonds of emerging countries issued in international financial markets. Data source: output, IFS; interest rates, EMBI+.

economies between 1994 and 2001. Periods of low interest rates are typically associated with economic expansions and times of high interest rates are often characterized by depressed levels of aggregate activity. ${ }^{1}$

The countercyclical behavior of country interest rates has spurred researchers to inves-

\footnotetext{
${ }^{1}$ The estimated correlations $(p$-values $)$ are: Argentina -0.67 (0.00), Brazil -0.51 (0.00), Ecuador -0.80 (0.00), Mexico -0.58 (0.00), Peru -0.37 (0.12), the Philippines -0.02 (0.95), South Africa -0.07 (0.71).
} 
tigate the role of movements in this variable in explaining business cycles in developing countries. In addressing this issue, an immediate natural question that emerges has to do with causality. Do country interest rates drive business cycles in emerging countries, or vice versa, or both? Different authors have approached this question in different ways.

One strand of the literature focuses primarily on stressing the effects of movements in domestic variables on country spreads. Specifically, a large empirical body of research has documented that country spreads respond systematically and countercyclically to business conditions in emerging economies. For instance, Cline (1995) and Cline and Barnes (1997) find that domestic variables such as GDP growth and export growth are significant determinants of country spreads in developing countries. Other studies have documented that higher credit ratings translate into lower country spreads (Cantor and Packer, 1996; Eichengreen and Mody, 1998). In turn, credit ratings have been found to respond strongly to domestic macroeconomic conditions. For example, Cantor and Packer (1996) estimate that about 80 percent of variations in credit ratings are explained by variations in per capita income, external debt burden, inflationary experience, default history, and the level of economic development. Cantor and Packer conclude, based on their own work and the related literature extant, that there exists significant information content of macroeconomic indicators in the pricing of sovereign risk. In this body of work little is said about the need to control for the fact that movements in domestic fundamentals may be caused in part by variations in country interest rates.

On the other extreme of the spectrum, a number of authors have assumed that country spreads are exogenous to domestic conditions in emerging countries. For instance, Neumeyer and Perri (2001) assume that the country spread and the US interest rate follow a bivariate, first-order, autoregressive process. They estimate such process and use it as a driving force of a theoretical model calibrated to Argentine data. In this way, Neumeyer and Perri assess the contribution of interest rates to explaining aggregate volatility in developing countries. They find that interest rate shocks explain 50 percent of output fluctuations in Argentina, and 
conclude, more generally, that they are an important factor for explaining business cycles in emerging countries.

If in reality country interest rates responded countercyclically to domestic conditions in emerging economies, then the findings of Neumeyer and Perri (2001) would be better interpreted as an upper bound on the contribution of country interest rates to business cycle fluctuations in emerging countries. For they rely on the presumption that movements in country interest rates are completely exogenous to domestic economic conditions. To illustrate how this exogeneity assumption can lead to an overestimation of the importance of country spreads in generating business cycle fluctuations, suppose that the (emerging) economy is hit by a positive productivity shock. In response to this innovation, output, investment, and consumption will tend to expand. Assume in addition that the country spread is a decreasing function of the level of economic activity. Then the productivity shock would also be associated with a decline in the spread. If in this economy one wrongly assumes that the spread is completely independent of domestic conditions, the change in the interest rate would be interpreted as an exogenous innovation, and therefore part of the accompanying expansion would be erroneously attributed to a spread shock, when in reality it was entirely caused by a domestic improvement in productivity.

Another important issue in understanding the macroeconomic effects of movements in country interest rates in emerging economies, is the role of world interest rates. Understanding the contribution of world interest rate shocks to aggregate fluctuations in developing countries is complicated by the fact that country interest rates do not respond one-for-one to movements in the world interest rate. In other words, emerging-country spreads respond to changes in the world interest rate. This fact has been documented in a number of studies (some of which are referenced above). Thus, country spreads serve as a transmission mechanism of world interest rates, capable of amplifying or dampening the effect of worldinterest-rate shocks on the domestic economy. Both because spreads depend on the world interest rate itself and because they respond to domestic fundamentals. 
In this paper, we attempt to disentangle the intricate interrelations between country spreads, the world interest rate, and business cycles in emerging countries. We do so using a methodology that combines empirical and theoretical analysis.

We begin by estimating a VAR system that includes measures of the world interest rate, the country interest rate, and a number of domestic macroeconomic variables. In estimating the model we use a panel dataset with seven emerging countries covering the period 19942001 at a quarterly frequency. Over the period considered, both country spreads and capital flows display significant movements in the countries included in our sample. We use the estimated empirical model to extract information about three aspects of the data: First, we identify country-spread shocks and US-interest-rate shocks. The essence of our identification scheme is to assume that innovations in international financial markets take one quarter to affect real domestic variables, whereas innovations in domestic product markets are picked up by financial markets contemporaneously. Second, we uncover the business cycles implied by the identified shocks by producing estimated impulse response functions. Third, we measure the importance of the two identified shocks in explaining movements in aggregate variables by performing a variance decomposition of the variables included in the empirical model.

To assess the plausibility of the spread shocks and US-interest-rate shocks that we identify with the empirical model, we are guided by theory. Specifically, we develop a simple model of a small open economy with four special features: gestation lags in the production of capital, external habit formation (or catching up with the Joneses), a working-capital constraint that requires firms to hold non-interest-bearing liquid assets in an amount proportional to their wage bill, and an information structure according to which, in each period, output and absorption decisions are made before that period's international financial conditions are revealed. The latter feature is consistent with the central assumption supporting the identification of our empirical model. We assign numerical values to the parameters of the model so as to fit a number of empirical regularities in developing countries. We then show that the model implies impulse response functions to country-spread shocks and to US- 
interest-rate shocks that are broadly consistent with those implied by the empirical model. It is in this precise sense that we conclude that the shocks identified in this study are plausible.

The main findings of the paper are: (1) US interest rate shocks explain about 20 percent of movements in aggregate activity in emerging countries at business-cycle frequency. (2) Country spread shocks explain about 12 percent of business-cycle movements in emerging economies. (3) About 60 percent of movements in country spreads are explained by country-spread shocks. (4) In response to an increase in US interest rates, country spreads first fall and then display a large, delayed overshooting. (5) US-interest-rate shocks affect domestic variables mostly through their effects on country spreads. Specifically, we find that when the country spread is assumed not to respond directly to variations in US interest rates, the standard deviation of output, investment, and the trade balance-to-output ratio explained by US-interest-rate shocks is about two thirds smaller. (6) The fact that country spreads respond to business conditions in emerging economies significantly exacerbates aggregate volatility in these countries. In particular, when the country spread is assumed to be independent of domestic conditions, the equilibrium volatility of output, investment, and the trade balance-to-output ratio explained jointly by US-interest-rate shocks and countryspread shocks falls by about one fourth.

The remainder of the paper is organized in four sections. In section 2, we present and estimate the empirical model, identify spread shocks and US-interest-rate shocks, and analyze the business cycles implied by these two sources of aggregate uncertainty. In section 3, we develop and parameterize the theoretical model and compare theoretical and empirical impulse response functions. In section 4, we investigate the business-cycle consequences of the fact that spreads respond to movements in both the US interest rate and domestic fundamentals. Section 5 closes the paper. 


\section{Empirical Analysis}

The goal of the empirical analysis presented here is to identify shocks to country spreads and the world interest rate and to assess their impact on aggregate activity in emerging economies. Our dataset consists of quarterly data over the period 1994:1 to 2001:4, for seven developing countries, Argentina, Brazil, Ecuador, Mexico, Peru, Philippine, and South Africa. Our choice of countries and sample period is guided by data availability. The countries we consider belong to the set of countries included in J. P. Morgan's EMBI+ dataset for emergingcountry spreads. In the EMBI+ database, time series for country spreads begin in 1994:1 or later. Of the 14 countries that were originally included in the EMBI+ database, we eliminated from our sample Morocco, Nigeria, Panama, and Venezuela, because quarterly data on output and/or the components of aggregate demand are unavailable, and Bulgaria, Poland, and Russia, because their transition from a centrally planned to a market-based economic organization in the early 1990s complicates the task of identifying the effects of interest rates at business-cycle frequencies.

\subsection{The Empirical Model}

Our empirical model takes the form of a first-order VAR system:

$$
A\left[\begin{array}{c}
\hat{y}_{t} \\
\hat{\imath}_{t} \\
t b y_{t} \\
\hat{R}_{t}^{u s} \\
\hat{R}_{t}
\end{array}\right]=B\left[\begin{array}{c}
\hat{y}_{t-1} \\
\hat{\imath}_{t-1} \\
t b y_{t-1} \\
\hat{R}_{t-1}^{u s} \\
\hat{R}_{t-1}
\end{array}\right]+\left[\begin{array}{c}
\epsilon_{t}^{y} \\
\epsilon_{t}^{i} \\
\epsilon_{t}^{t b y} \\
\epsilon_{t}^{r u s} \\
\epsilon_{t}^{r}
\end{array}\right]
$$

where $y_{t}$ denotes real gross domestic output, $i_{t}$ denotes real gross domestic investment, $t b y_{t}$ denotes the trade balance to output ratio, $R_{t}^{u s}$ denotes the gross real US interest rate, and $R_{t}$

denotes the gross real (emerging) country interest rate. A hat on top of $y_{t}$ and $i_{t}$ denotes $\log$ 
deviations from a log-linear trend. A hat on $R_{t}^{u s}$ and $R_{t}$ denotes simply the log. We measure $R_{t}^{u s}$ as the 3-month gross Treasury bill rate divided by the average gross US inflation over the past four quarters. ${ }^{2}$ We measure $R_{t}$ as the sum of J. P. Morgan's EMBI+ stripped spread and the US real interest rate. Output, investment, and the trade balance are seasonally adjusted. More details on the data are provided in appendix B.

We identify our VAR model by imposing the restriction that the matrix $A$ be lower triangular with unit diagonal elements. Because $R_{t}^{u s}$ and $R_{t}$ appear at the bottom of the system, our identification strategy presupposes that innovations in world interest rates $\left(\epsilon_{t}^{r u s}\right)$ and innovations in country interest rates $\left(\epsilon_{t}^{r}\right)$ percolate into domestic real variables with a one-period lag. At the same time, the identification scheme implies that real domestic shocks $\left(\epsilon_{t}^{y}, \epsilon_{t}^{i}\right.$, and $\left.\epsilon_{t}^{t b y}\right)$ affect financial markets contemporaneously. We believe our identification strategy is a natural one, for, conceivably, decisions such as employment and spending on durable consumption goods and investment goods take time to plan and implement. Also, it seems reasonable to assume that financial markets are able to react quickly to news about the state of the business cycle in emerging economies. ${ }^{3}$

Note that the order of the first three variables in our $\operatorname{VAR}\left(\hat{y}_{t}, \hat{\imath}_{t}\right.$, and $\left.t b y_{t}\right)$ does not affect either our estimates of the US-interest-rate and country-interest-rate shocks ( $\epsilon_{t}^{\text {rus }}$ and $\left.\epsilon_{t}^{r}\right)$ or the impulse responses of output, investment, and the trade balance to innovations in these two sources of aggregate fluctuations.

We further note that the country-interest-rate shock, $\epsilon_{t}^{r}$, can equivalently be interpreted as a country spread shock. To see this, consider substituting in equation (1) the country

\footnotetext{
${ }^{2}$ Using a more forward looking measure of inflation expectations to compute the US real interest rate does not significantly alter our main results.

${ }^{3}$ But alternative ways to identify $\epsilon_{t}^{r u s}$ and $\epsilon_{t}^{r}$ are also possible. In appendix A, we explore an identification scheme that allows for real domestic variables to react contemporaneously to innovations in the US interest rate or the country spread. Under this alternative identification strategy, the point estimate of the impact of a US-interest-rate shock on output and investment is slightly positive. For both variables, the two-standarderror intervals around the impact effect include zero (see figure 8). Because it would be difficult for most models of the open economy to predict an expansion in output and investment in response to an increase in the world interest rate, we conclude that our maintained identification assumption that real variables do not react contemporaneously to innovations in external financial variables is more plausible than the alternative described here.
} 
interest rate $\hat{R}_{t}$ using the definition of country spread, $\hat{S}_{t} \equiv \hat{R}_{t}-\hat{R}_{t}^{u s}$. Clearly, because $R_{t}^{u s}$ appears as a regressor in the bottom equation of the VAR system, the estimated residual of the newly defined bottom equation, call it $\epsilon_{t}^{s}$, is identical to $\epsilon_{t}^{r}$. Moreover, it is obvious that the impulse response functions of $\hat{y}_{t}, \hat{\imath}_{t}$, and $t b y_{t}$ associated with $\epsilon_{t}^{s}$ are identical to those associated with $\epsilon_{t}^{r}$. Therefore, throughout the paper we indistinctly refer to $\epsilon_{t}^{r}$ as a country interest rate shock or as a country spread shock.

We estimate the VAR system (1) equation by equation using an instrumental-variable method for dynamic panel data. ${ }^{4}$ The estimation results are shown in table 1 . The estimated system includes an intercept and country specific fixed effects (not shown in the table). We include a single lag in the VAR. In choosing the lag length of the VAR system, we perform the Akaike Information Criterion (AIC) and general-to-specific likelihood ratio tests. Both tests select a vector autoregression of first order. In estimating the VAR system, we assume that $R_{t}^{u s}$ follows a simple univariate $A R(1)$ process (i.e., we impose the restriction $A_{4 i}=B_{4 i}=0$, for all $\left.i \neq 4\right)$. We adopt this restriction for a number of reasons. First, it is reasonable to assume that disturbances in a particular (small) emerging country will not affect the real interest rate of a large country like the United States. Second, the assumed $\mathrm{AR}(1)$ specification for $R_{t}^{u s}$ allows us to use a longer time series for $R^{u s}$ in estimating the fourth equation of the VAR system, which delivers a tighter estimate of the autoregressive coefficient $B(4,4)$. (Note that $R_{t}^{u s}$ is the only variable in the VAR system that does not change from country to country.) Lastly, the unrestricted estimate of the $R_{t}^{u s}$ equation features statistically insignificant coefficients on all variables except those associated with the lagged US interest rate $\left(B_{44}\right)$ and the contemporaneous trade balance-to-GDP ratio $\left(A_{43}\right)$. In addition, the point estimate of $A_{43}$ is small. ${ }^{5}$ We suspect that the positive coefficient

\footnotetext{
${ }^{4}$ Our model is a dynamic panel data model with unbalanced long panels $(T>30)$. The model is estimated using the Anderson and Hsiao's (1981) procedure, with lagged levels serving as instrument variables. Judson and Owen (1999) find that compared to the GMM estimator proposed by Arellano and Bond (1991) or the least square estimator with (country specific) dummy variables, the Anderson-Hsiao estimator produces the lowest estimate bias for dynamic panel models with $T>30$.

${ }^{5}$ In effect, the point estimate of $A_{4,3}$ is 0.082 , which implies that a large increase in the trade balance of 1 percentage point of GDP $\left(\Delta t b y_{t}=0.01\right)$ produces an increase in the US interest rate of 0.08 percentage points.
} 
on $t_{b y}$ in the $R_{t}^{u s}$ equation is reflective of omitted domestic US variables, particularly variables measuring US aggregate activity. This is because in periods of economic expansion in the United States, the Fed typically tightens monetary policy. At the same time, during expansions the US economy typically runs trade balance deficits, which means that those small countries that export primarily to the United States are likely to run trade surpluses during such periods. These omitted variables would contaminate our estimate of $\epsilon_{t}^{r u s}$ insofar as domestic US shocks transmit to emerging market economies through channels other than the US interest rate, such as the terms of trade. Obviously, our estimate of world interest rate shocks depend crucially on the maintained specification of the fourth equation in the VAR system. But clearly the estimate of the country spread shocks is independent of the particular specification assumed for the fourth equation of the VAR system. Using the unrestricted estimate of the $R_{t}^{u s}$ equation delivers impulse responses to US interest rate shocks that are similar to those implied by the AR(1) specification but with much wider error bands around them. ${ }^{6}$ We estimate the $A R(1)$ process for $R_{t}^{u s}$ for the period 1987:Q3 to 2002:Q4. This sample period corresponds to the Greenspan era, which arguably ensures homogeneity in the monetary policy regime in place in the United States.

\subsection{Country Spreads, US Interest Rates, and Business Cycles}

With an estimate of the VAR system (1) at hand, we can address four central questions: First, how do US-interest-rate shocks and country-spread shocks affect real domestic variables such as output, investment, and the trade balance? Second, how do country spreads respond to innovations in US interest rates? Third, how and by how much do country spreads move in response to innovations in emerging-country fundamentals? Fourth, how important are USinterest-rate shocks and country-spread shocks in explaining movements in aggregate activity in emerging countries? Fifth, how important are US-interest-rate shocks and country-spread shocks in accounting for movements in country spreads? We answer these questions with

\footnotetext{
${ }^{6}$ The results are available from the authors upon request.
} 
the help of impulse response functions and variance decompositions.

\subsubsection{Impulse Response Functions}

Figure 2 displays with solid lines the impulse response function implied by the VAR sys-

Figure 2: Impulse Response To Country-Spread Shock
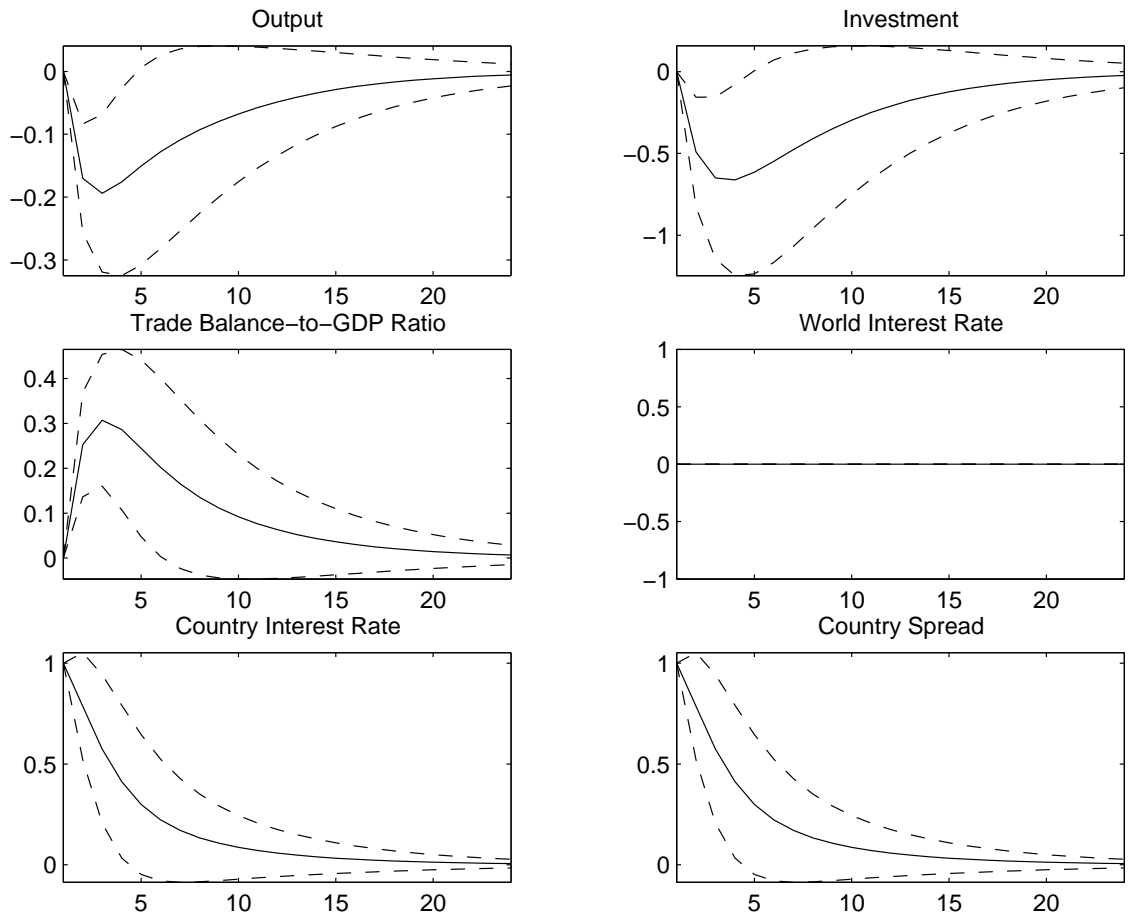

Notes: (1) Solid lines depict point estimates of impulse responses, and broken lines depict two-standard-deviation error bands. (2) The responses of Output and Investment are expressed in percent deviations from their respective log-linear trends. The responses of the Trade Balance-to-GDP ratio, the country interest rate, the US interest rate, and the country spread are expressed in percentage points. The two-standard-error bands are computed using the delta method.

tem (1) to a unit innovation in the country spread shock, $\epsilon_{t}^{r}$. Broken lines depict twostandard-deviation bands. ${ }^{7}$ In response to an unanticipated country-spread shock, the country spread itself increases and then quickly falls toward its steady-state level. The half life of

\footnotetext{
${ }^{7}$ These bands are computed using the delta method.
} 
the country spread response is about one year. Output, investment, and the trade balanceto-output ratio respond as one would expect. They are unchanged in the period of impact, because of our maintained assumption that external financial shocks take one quarter to affect production and absorption. In the two periods following the country-spread shock, output and investment fall, and subsequently recover gradually until they reach their preshock level. The adverse spread shock produces a larger contraction in aggregate domestic absorption than in aggregate output. This is reflected in the fact that the trade balance improves in the two periods following the shock.

Figure 3 displays the response of the variables included in the VAR system (1) to a one

Figure 3: Impulse Response To A US-Interest-Rate Shock
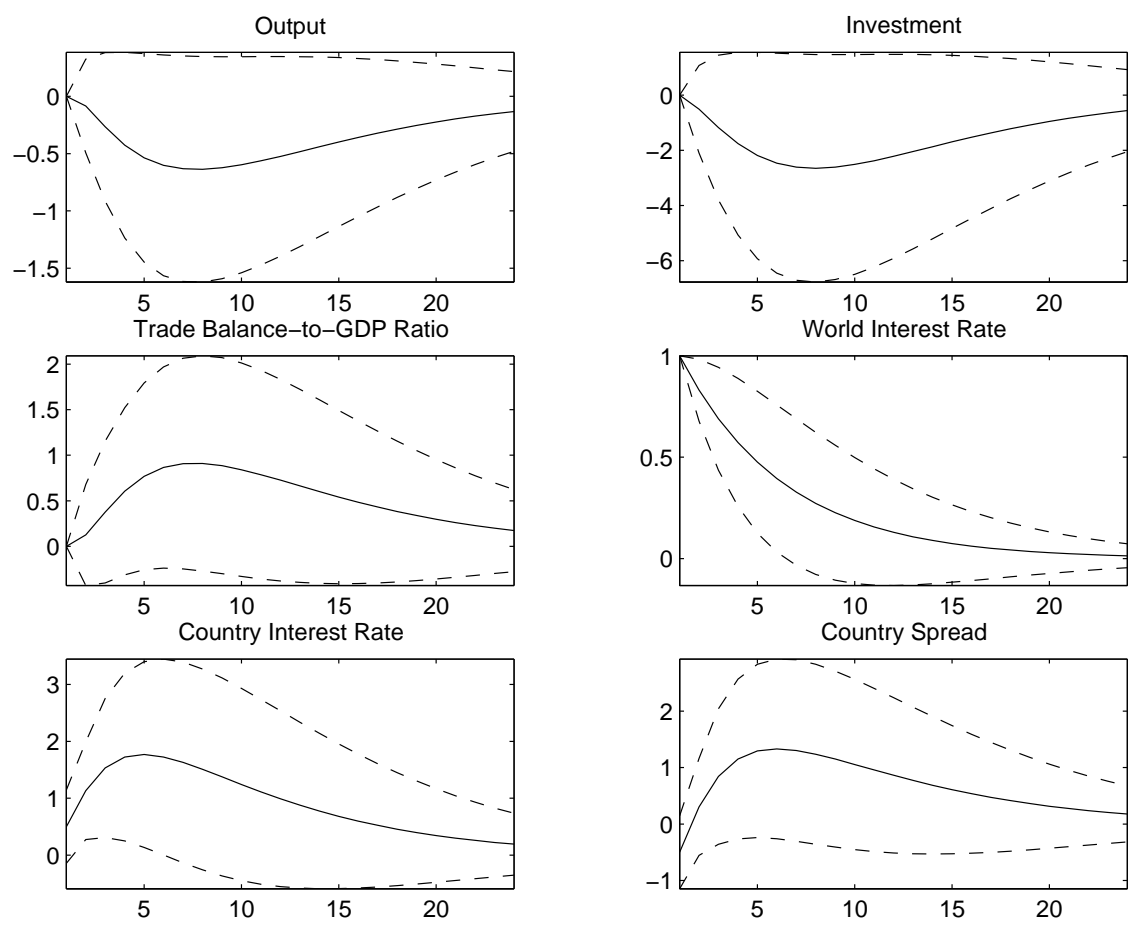

Notes: (1) Solid lines depict point estimates of impulse responses, and broken lines depict two-standard-deviation error bands. (2) The responses of Output and Investment are expressed in percent deviations from their respective loglinear trends. The responses of the Trade Balance-to-GDP ratio, the country interest rate, and the US interest rate are expressed in percentage points. 
percentage point increase in the US interest rate shock, $\epsilon_{t}^{r u s}$. A remarkable feature of this impulse response fnction is that the country spread displays a delayed overshooting. In effect, in the period of impact, the country interest rate increases but by less than the jump in the US interest rate. As a result, the country spread initially falls. However, the country spread recovers quickly and after a couple of quarters it is more than one percentage point above its pre-shock level. Thus, country spreads respond strongly to innovations in the US interest rate but with a short delay. ${ }^{8}$ The responses of output, investment, and the trade balance are qualitatively similar to those associated with an innovation in the country spread. That is, aggregate activity and gross domestic investment contract, while net exports improve. However, the quantitative effects of an innovation in the US interest rate are much more pronounced than those caused by a country-spread disturbance of equal magnitude. For instance, the trough in the output response is twice as large under a US-interest-rate shock than under a country-spread shock.

We now ask how innovations in the output shock $\epsilon_{t}^{y}$ impinge upon the variables of our empirical model. The model is vague about the precise nature of output shocks. They can reflect variations in total factor productivity, terms-of-trade movements, etc. Figure 4 depicts the impulse response function to a one-percent increase in the output shock. The response of output, investment, and the trade balance is very much in line with the impulse response to a positive productivity shock implied by the small open economy $\mathrm{RBC}$ model (see e.g., Schmitt-Grohé and Uribe, 2003). The response of investment is about three times as large as that of output. At the same time, the trade balance deteriorates significantly for two periods by about 0.4 percent and then converges gradually to its steady-state level. More interestingly, the increase in output produces a significant reduction in the country spread of about 0.6 percent. The half life of the country spread response is about five quarters. The countercyclical behavior of the country spread in response to output shocks suggests that

\footnotetext{
${ }^{8}$ The negative impact effect of an increase in the US interest rate on the country spread is in line with the findings of Eichengreen and Mody (1998) and Kamin and Kleist (1999). We note, however, that because the models estimated in these studies are static in nature, by construction, they are unable to capture the rich dynamic relation linking the two variables.
} 
Figure 4: Impulse Response To An Output Shock
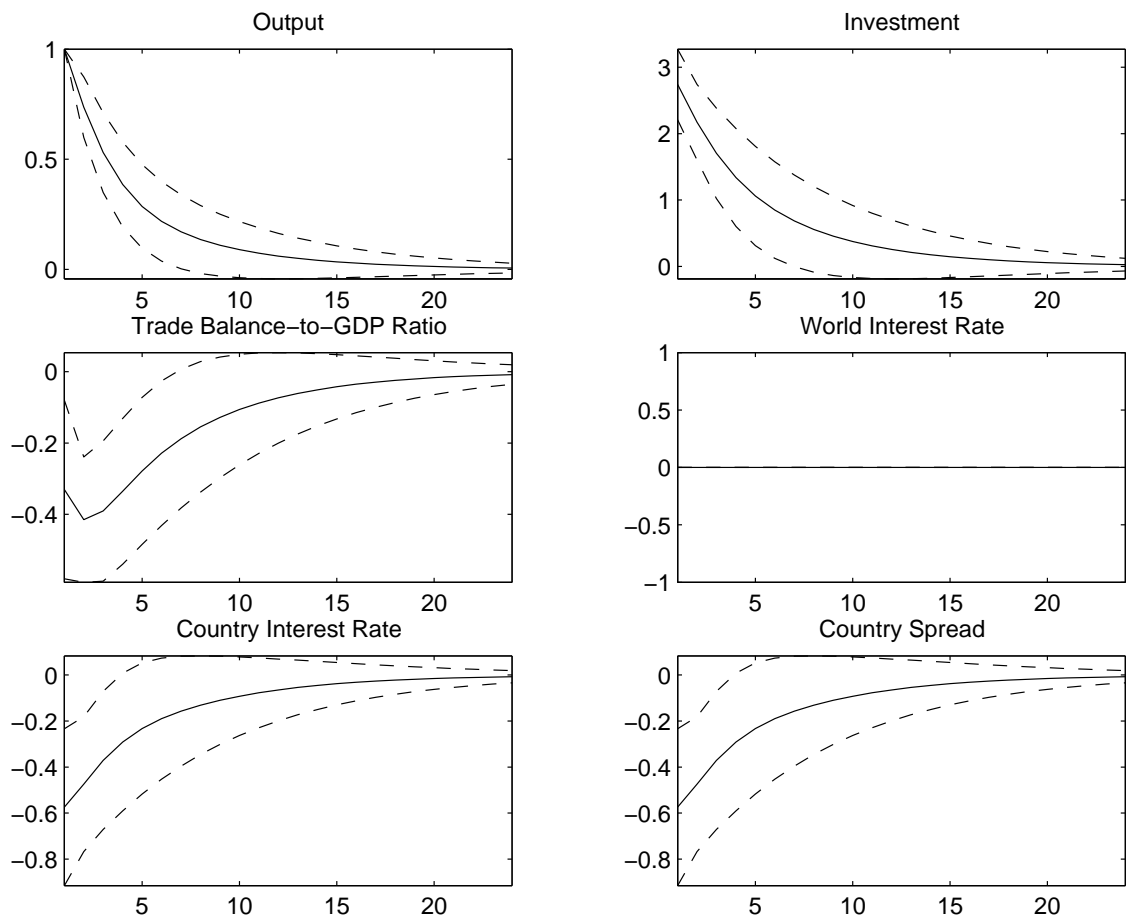

Notes: (1) Solid lines depict point estimates of impulse response functions, and broken lines depict two-standard-deviation error bands. (2) The responses of Output and Investment are expressed in percent deviations from their respective log-linear trends. The responses of the Trade Balance-to-GDP ratio, the country interest rate, and the US interest rate are expressed in percentage points.

country interest rates behave in ways that exacerbates the business-cycle effects of output shocks.

\subsubsection{Variance Decompositions}

Figure 5 displays the variance decomposition of the variables contained in the VAR system (1) at different horizons. Solid lines show the fraction of the variance of the forecasting error explained jointly by US-interest-rate shocks and country-spread shocks $\left(\epsilon_{t}^{r u s}\right.$ and $\left.\epsilon_{t}^{r}\right)$. Broken lines depict the fraction of the variance of the forecasting error explained by US-interestrate shocks $\left(\epsilon_{t}^{r u s}\right)$. Because $\epsilon_{t}^{r u s}$ and $\epsilon_{t}^{r}$ are orthogonal disturbances, the vertical difference 
Figure 5: Variance Decomposition at Different Horizons
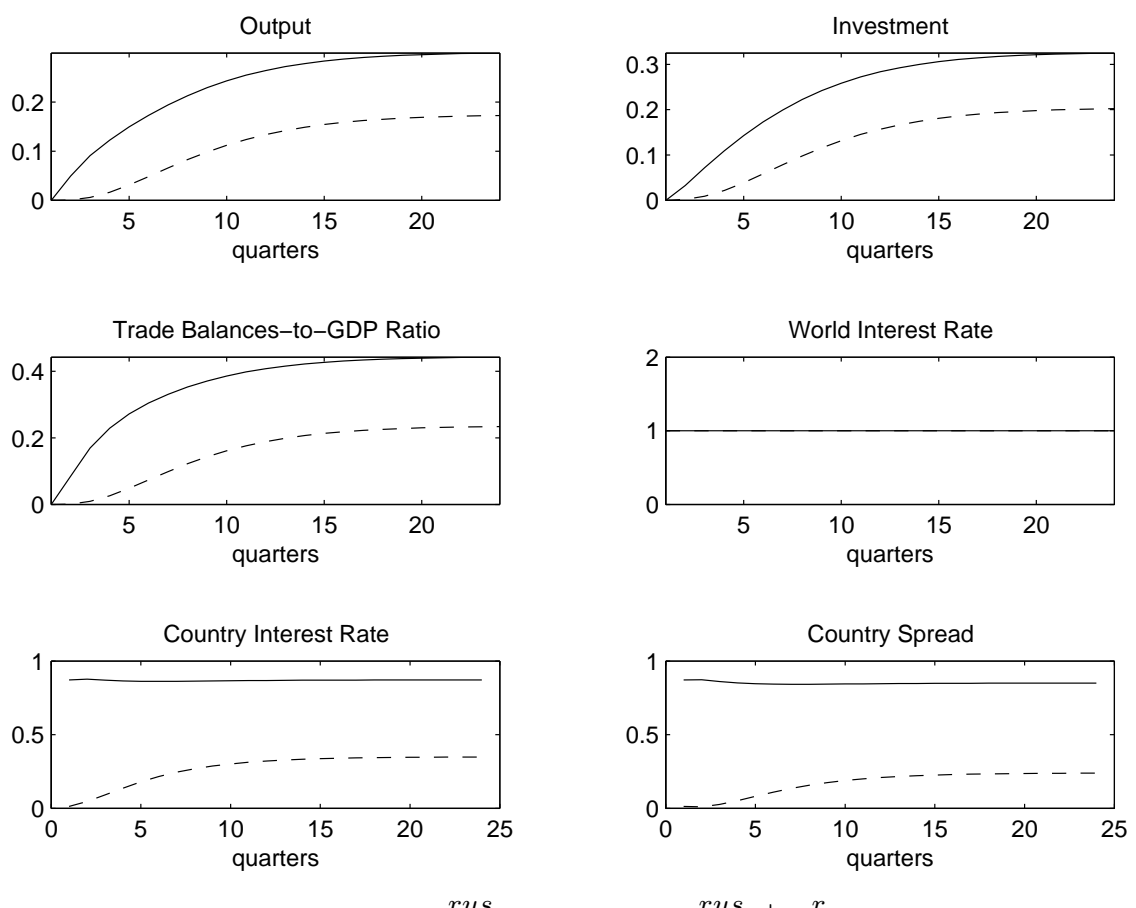

$$
\text { - - } \epsilon^{\text {rus }}-\epsilon^{\text {rus }}+\epsilon^{r}
$$

Note: Solid lines depict the fraction of the variance of the k-quarter-ahead forecasting error explained jointly by $\epsilon_{t}^{r u s}$ and $\epsilon_{t}^{r}$ at different horizons. Broken lines depict the fraction of the variance of the forecasting error explained by $\epsilon_{t}^{r u s}$ at different horizons.

between solid and broken lines represents the variance of the forecasting error explained 
by country-spread shocks at different horizons. ${ }^{9,10}$ Note that as the forecasting horizon approaches infinity, the decomposition of the variance of the forecasting error coincides with the decomposition of the unconditional variance of the series in question.

For the purpose of the present discussion, we associate business-cycle fluctuations with the variance of the forecasting error at a horizon of about five years. Researchers typically define business cycles as movements in time series of frequencies ranging from 6 quarters to 32 quarters (Stock and Watson, 1999). Our choice of horizon falls in the middle of this window.

According to our estimate of the VAR system given in equation (1), innovations in the US interest rate, $\epsilon_{t}^{\text {rus }}$, explain about 20 percent of movements in aggregate activity in emerging countries at business cycle frequency. At the same time, country-spread shocks, $\epsilon_{t}^{r}$, account for about 12 percent of aggregate fluctuations in these countries. Thus, around one third of business cycles in emerging economies is explained by disturbances in external financial variables. These disturbances play an even stronger role in explaining movements in international transactions. In effect, US-interest-rate shocks and country-spread shocks are responsible for about 43 percent of movements in the trade balance-to-output ratio in the countries included in our panel.

${ }^{9}$ These forecasting errors are computed as follows. Let $x_{t} \equiv\left[\hat{y}_{t} \hat{\imath}_{t} t b y_{t} \hat{R}_{t}^{u s} \hat{R}_{t}\right]$ be the vector of variables included in the VAR system and $\epsilon_{t} \equiv\left[\epsilon_{t}^{y} \epsilon_{t}^{i} \epsilon_{t}^{t b y} \epsilon_{t}^{r u s} \epsilon_{t}^{r}\right]$ the vector of disturbances of the VAR system. Then, one can write the $\operatorname{MA}(\infty)$ representation of $x_{t}$ as $x_{t}=\sum_{j=0}^{\infty} C_{j} \epsilon_{t-j}$, where $C_{j} \equiv\left(A^{-1} B\right)^{j} A^{-1}$. The error in forecasting $x_{t+h}$ at time $t$ for $h>0$, that is, $x_{t+h}-E_{t} x_{t+h}$, is given by $\sum_{j=0}^{h} C_{j} \epsilon_{t+h-j}$. The variance/covariance matrix of this $h$-step-ahead forecasting error is given by $\Sigma^{x, h} \equiv \sum_{j=0}^{h} C_{j} \Sigma_{\epsilon} C_{j}^{\prime}$, where $\Sigma_{\epsilon}$ is the (diagonal) variance/covariance matrix of $\epsilon_{t}$. Thus, the variance of the $h$-step-ahead forecasting error of $x_{t}$ is simply the vector containing the diagonal elements of $\Sigma^{x, h}$. In turn, the variance of the error of the $h$-step-ahead forecasting error of $x_{t}$ due to a particular shock, say $\epsilon_{t}^{r u s}$, is given by the diagonal elements of the matrix $\Sigma^{x, \epsilon^{r u s}, h} \equiv \sum_{j=0}^{h}\left(C_{j} \Lambda_{4}\right) \Sigma_{\epsilon}\left(C_{j} \Lambda_{4}\right)^{\prime}$, where $\Lambda_{4}$ is a $5 \times 5$ matrix with all elements equal to zero except element $(4,4)$, which takes the value one. Then, the broken lines in figure 5 are given by the element-by-element ratio of the diagonal elements of $\Sigma^{x, \epsilon^{r u s}, h}$ to the diagonal elements of the matrix $\Sigma^{x, h}$ for different values of $h$. The difference between the solid lines and the broken lines (i.e., the fraction of the variance of the forecasting error due to $\epsilon_{t}^{r}$ ) is computed in a similar fashion but using the matrix $\Lambda_{5}$.

${ }^{10}$ We observe that the estimates of $\epsilon_{t}^{y}, \epsilon_{t}^{i}, \epsilon_{t}^{t b y}$, and $\epsilon_{t}^{r}$ (i.e., the sample residuals of the first, second, third, and fifth equations of the VAR system) are orthogonal to each other. But because $\hat{y}_{t}$, $\hat{i}_{t}$, and $t b y_{t}$ are excluded from the $R_{t}^{u s}$ equation, we have that the estimates of $\epsilon_{t}^{r u s}$ will in general not be orthogonal to the estimates of $\epsilon_{t}^{y}, \epsilon_{t}^{i}$, or $\epsilon_{t}^{t b y}$. However, under our maintained specification assumption that the US real interest rate does not systematically respond to the state of the business cycle in emerging countries, this lack of orthogonality should disappear as the sample size increases. 
Variations in country spreads are largely explained by innovations in US interest rates and innovations in country-spreads themselves. Jointly, these two sources of uncertainty account for about 85 percent of fluctuations in country spreads. Most of this fraction, about 60 percentage points, is attributed to country-spread shocks. This last result concurs with Eichengreen and Mody (1998), who interpret this finding as suggesting that arbitrary revisions in investors sentiments play a significant role in explaining the behavior of country spreads.

The impulse response functions shown in figure 4 establish empirically that country spreads respond significantly and systematically to domestic macroeconomic variables. At the same time, the variance decomposition performed in this section indicates that domestic variables are responsible for about 15 percent of the variance of country spreads at businesscycle frequency. A natural question raised by these findings is whether the feedback from endogenous domestic variables to country spreads exacerbates domestic volatility. Here we make a first step at answering this question. Specifically, we modify the $\hat{R}_{t}$ equation of the VAR system by setting to zero the coefficients on $\hat{y}_{t-i}, \hat{i}_{t-i}$, and $t b y_{t-i}$ for $i=0,1$. We then compute the implied volatility of $\hat{y}_{t}, \hat{i}_{t}, t b y_{t}$ and $\hat{R}_{t}$ in the modified VAR system at businesscycle frequency (20 quarters). We compare these volatilities to those emerging from the original VAR model. Table 2 shows that the presence of feedback from domestic variables to country spreads significantly increases domestic volatility. In particular, when we shut off the endogenous feedback, the volatility of output falls by 16 percent whereas the volatility of investment and the trade balance-to-GDP ratio falls by about 20 percent. The effect of feedback on the cyclical behavior of the country spread itself if even stronger. In effect, when feedback is negated, the volatility of the country interest rate falls by about one third.

Of course, this counterfactual exercise is subject to Lucas' (1976) celebrated critique. For one should not expect that in response to changes in the coefficients defining the spread process all other coefficients of the VAR system will remain unaltered. As such, the results of table 2 serve solely as a way to motivate a more adequate approach to the question they 
aim to address. This more satisfactory approach necessarily involves the use of a theoretical model economy where private decisions change in response to alterations in the countryspread process. We follow this route later on.

\section{$3 \quad$ Plausibility of the Identified Shocks}

The process of identifying country-spread shocks and US-interest-rate shocks involves a number of restrictions on the matrices defining the VAR system (1). To assess the plausibility of these restrictions, it is necessary to use the predictions of some theory of the business cycle as a metric. If the estimated shocks imply similar business cycle fluctuations in the empirical as in theoretical models, we conclude that according to the proposed theory, the identified shocks are plausible.

Accordingly, we will assess the plausibility of our estimated shocks in four steps: First, we develop a standard model of the business cycle in small open economies. Second, we estimate the deep structural parameters of the model. Third, we feed into the model the estimated version of the fourth and fifth equations of the VAR system (1), describing the stochastic laws of motion of the US interest rate and the country spread. Finally, we compare estimated impulse responses (i.e., those shown in figures 2 and 3) with those implied by the proposed theoretical framework.

\subsection{The Theoretical Model}

The basis of the theoretical model presented here is the standard neoclassical growth model of the small open economy (e.g., Mendoza, 1991). We depart from the canonical version of the model in four important dimensions. First, as in the empirical model, we assume that in each period, production and absorption decisions are made prior to the realization of that period's world interest rate and country spread. Thus, innovations in the world interest rate or the country spread are assumed to have allocative effects with a one-period 
lag. Second, preferences are assumed to feature external habit formation, or catching up with the Joneses as in Abel (1990). This feature improves the predictions of the standard model by preventing an excessive contraction in private non-business absorption in response to external financial shocks. Habit formation has been shown to help explain asset prices and business fluctuations in both developed economies (e.g., Boldrin, Christiano, and Fisher, 2001) and emerging countries (e.g., Uribe, 2002). Third, firms are assumed to be subject to a working-capital-in-advance constraint. This element introduces a direct supply side effect of changes in the cost of borrowing in international financial markets. This working capital constraint allows the model to predict a more realistic response of domestic output to external financial shocks. Fourth, the process of capital accumulation is assumed to be subject to gestation lags and convex adjustment costs. In combination, these frictions prevent excessive investment volatility, induce persistence, and allow for the observed nonmonotonic (hump-shaped) response of investment in response to a variety of shocks (see Uribe, 1997).

\subsubsection{Households}

Consider a small open economy populated by a large number of infinitely lived households with preferences described by the following utility function

$$
E_{0} \sum_{t=0}^{\infty} \beta^{t} U\left(c_{t}-\mu \tilde{c}_{t-1}, h_{t}\right)
$$

where $c_{t}$ denotes consumption in period $t, \tilde{c}_{t}$ denotes the cross-sectional average level of consumption in period $t-1$, and $h_{t}$ denotes the fraction of time devoted to work in period $t$. Households take as given the process for $\tilde{c}_{t}$. The single-period utility index $u$ is assumed to be increasing in its first argument, decreasing in its second argument, concave, and smooth. The parameter $\beta \in(0,1)$ denotes the subjective discount factor. The parameter $\mu$ measures the degree of external habit formation. The case $\mu=0$ corresponds to time separability in preferences. The larger is $\mu$, the stronger is the degree of external habit formation. 
Households have access to two types of asset, physical capital and an internationally traded bond. The capital stock is assumed to be owned entirely by domestic residents. Households have three sources of income: wages, capital rents, and interest income on financial asset holdings. Each period, households allocate their wealth to purchases of consumption goods, purchases of investment goods, and purchases of financial assets. The household's period-by-period budget constraint is given by

$$
d_{t}=R_{t-1} d_{t-1}+\Psi\left(d_{t}\right)-w_{t} h_{t}-u_{t} k_{t}+c_{t}+i_{t}
$$

where $d_{t}$ denotes the household's debt position in period $t, R_{t}$ denotes the gross interest rate faced by domestic residents in financial markets, $w_{t}$ denotes the wage rate, $u_{t}$ denotes the rental rate of capital, $k_{t}$ denotes the stock of physical capital, and $i_{t}$ denotes gross domestic investment. We assume that households face costs of adjusting their foreign asset position. We introduce these adjustment costs with the sole purpose of eliminating the familiar unit root built in the dynamics of standard formulations of the small open economy model. The debt-adjustment cost function $\Psi(\cdot)$ is assumed to be convex and to satisfy $\Psi(\bar{d})=\Psi^{\prime}(\bar{d})=0$, for some $\bar{d}>0$. Schmitt-Grohé and Uribe (2003) compare a number of standard alternative ways to induce stationarity in the small open economy framework and conclude that they all produce virtually identical implications for business fluctuations.

The debt adjustment cost can be decentralized as follows. Suppose that financial transactions between domestic and foreign residents require financial intermediation by domestic institutions (banks). Suppose there is a continuum of banks of measure one that behave competitively. They capture funds from foreign investors at the country rate $R_{t}$ and lend to domestic agents at the rate $R_{t}^{d}$. In addition, banks face operational costs, $\Psi\left(d_{t}\right)$, that are increasing and convex in the volume of intermediation, $d_{t}$. The problem of domestic banks is then to choose the volume $d_{t}$ so as to maximize profits, which are given by $R_{t}^{d}\left[d_{t}-\Psi\left(d_{t}\right)\right]-R_{t} d_{t}$, taking as given $R_{t}^{d}$ and $R_{t}$. It follows from the first-order condition 
associated with this problem that the interest rate charged to domestic residents is given by

$$
R_{t}^{d}=\frac{R_{t}}{1-\Psi^{\prime}\left(d_{t}\right)},
$$

which is precisely the shadow interest rate faced by domestic agents in the centralized problem (see the Euler condition (11) below). Bank profits are assumed to be distributed to domestic households in a lump-sum fashion. This digression will be of use later in the paper when we analyze the firm's problem.

The process of capital accumulation displays adjustment costs in the form of gestation lags and convex costs of installing new capital goods. To produce one unit of capital good requires investing $1 / 4$ units of goods for four consecutive periods. Let $s_{i t}$ denote the number of investment projects started in $t-i$ for $i=0,1,2,3$. Then investment in period $t$ is given by

$$
i_{t}=\frac{1}{4} \sum_{i=0}^{3} s_{i t} .
$$

In turn, the evolution of $s_{i t}$ is given by

$$
s_{i+1 t+1}=s_{i t},
$$

For $i=0,1,2$. The stock of capital obeys the following law of motion:

$$
k_{t+1}=(1-\delta) k_{t}+k_{t} \Phi\left(\frac{s_{3 t}}{k_{t}}\right),
$$

where $\delta \in(0,1)$ denotes the rate of depreciation of physical capital. The process of capital accumulation is assumed to be subject to adjustment costs, as defined by the function $\Phi$, which is assumed to be strictly increasing, concave, and to satisfy $\Phi(\delta)=\delta$ and $\Phi^{\prime}(\delta)=1$. These last two assumptions ensure the absence of adjustment costs in the steady state. The introduction of capital adjustment costs is commonplace in models of the small open economy. They are a convenient and plausible way to avoid excessive investment volatility 
in response to changes in the interest rate faced by the country in international markets.

Households choose contingent plans $\left\{c_{t+1}, h_{t+1}, s_{0, t+1}, d_{t+1}\right\}_{t=0}^{\infty}$ so as to maximize the utility function (2) subject to the budget constraint (3), the laws of motion of total investment, investment projects, and the capital stock given by equations (5)-(7), and a borrowing constraint of the form

$$
\lim _{j \rightarrow \infty} E_{t} \frac{d_{t+j+1}}{\prod_{s=0}^{j} R_{t+s}} \leq 0
$$

that prevents the possibility of Ponzi schemes. The household takes as given the processes $\left\{\tilde{c}_{t-1}, R_{t}, w_{t}, u_{t}\right\}_{t=0}^{\infty}$ as well as $c_{0}, h_{0}, k_{0}, R_{-1} d_{-1}$, and $s_{i t}$ for $i=0,1,2,3$. The Lagrangian associated with the household's optimization problem can be written as:

$$
\begin{aligned}
\mathcal{L} & =E_{0} \sum_{t=0}^{\infty} \beta^{t}\left\{U\left(c_{t}-\mu \tilde{c}_{t-1}, h_{t}\right)+\lambda_{t}\left[d_{t}-R_{t-1} d_{t-1}-\Psi\left(d_{t}\right)+w_{t} h_{t}+u_{t} k_{t}-\frac{1}{4} \sum_{i=0}^{3} s_{i t}-c_{t}\right]\right. \\
& \left.+\lambda_{t} q_{t}\left[(1-\delta) k_{t}+k_{t} \Phi\left(\frac{s_{3 t}}{k_{t}}\right)-k_{t+1}\right]+\lambda_{t} \sum_{i=0}^{2} \nu_{i t}\left(s_{i t}-s_{i+1 t+1}\right)\right\}
\end{aligned}
$$

where $\lambda_{t}, \lambda_{t} \nu_{i t}$, and $\lambda_{t} q_{t}$ are the Lagrange multipliers associated with constraints (3), (6), and (7), respectively. The optimality conditions associated with the household's problem are (3), (5)-(8) all holding with equality and

$$
\begin{gathered}
E_{t} \lambda_{t+1}=U_{c}\left(c_{t+1}-\mu \tilde{c}_{t}, h_{t+1}\right) \\
E_{t}\left[w_{t+1} \lambda_{t+1}\right]=-U_{h}\left(c_{t+1}-\mu \tilde{c}_{t}, h_{t+1}\right) \\
\lambda_{t}\left[1-\Psi^{\prime}\left(d_{t}\right)\right]=\beta R_{t} E_{t} \lambda_{t+1} \\
E_{t} \lambda_{t+1} \nu_{0 t+1}=\frac{1}{4} E_{t} \lambda_{t+1} \\
\beta E_{t} \lambda_{t+1} \nu_{1 t+1}=\frac{\beta}{4} E_{t} \lambda_{t+1}+\lambda_{t} \nu_{0 t} \\
\beta E_{t} \lambda_{t+1} \nu_{2 t+1}=\frac{\beta}{4} E_{t} \lambda_{t+1}+\lambda_{t} \nu_{1 t}
\end{gathered}
$$




$$
\begin{gathered}
\beta E_{t}\left[\lambda_{t+1} q_{t+1} \Phi^{\prime}\left(\frac{s_{3 t+1}}{k_{t+1}}\right)\right]=\frac{\beta}{4} E_{t} \lambda_{t+1}+\lambda_{t} \nu_{2 t} \\
\lambda_{t} q_{t}=\beta E_{t}\left\{\lambda_{t+1} q_{t+1}\left[1-\delta+\Phi\left(\frac{s_{3 t+1}}{k_{t+1}}\right)-\frac{s_{3 t+1}}{k_{t+1}} \Phi^{\prime}\left(\frac{s_{3 t+1}}{k_{t+1}}\right)\right]+\lambda_{t+1} u_{t+1}\right\} .
\end{gathered}
$$

The interpretation of these equations is straightforward. It is important to recall, however, that, because of our assumed information structure, the variables $c_{t+1}, h_{t+1}$, and $s_{0 t+1}$ all reside in the information set of period $t$. Equation (9) states that in period $t$ households choose consumption and leisure for period $t+1$ in such as way as to equate the marginal utility of consumption in period $t+1$ to the expected marginal utility of wealth in that period, $E_{t} \lambda_{t+1}$. Note that in general the marginal utility of wealth will differ from the marginal utility of consumption $\left(\lambda_{t} \neq U_{c}\left(c_{t}-\mu \tilde{c}_{t-1}, h_{t}\right)\right)$, because current consumption cannot react to unanticipated changes in wealth. Equation (10) defines the household's labor supply schedule, by equating the marginal disutility of effort in period $t+1$ to the expected utility value of the wage rate in that period. Equation (11) is an asset pricing relation equating the intertemporal marginal rate of substitution in consumption to the rate of return on financial assets. Note that, because of the presence of frictions to adjust bond holdings, the relevant rate of return on this type of asset is not simply the market rate $R_{t}$ but rather the shadow rate of return $R_{t} /\left[1-\Psi^{\prime}\left(d_{t}\right)\right]$. Intuitively, when the household's debt position is, say, above its steady-state level $\bar{d}$, we have that $\Psi^{\prime}\left(d_{t}\right)>0$ so that the shadow rate of return is higher than the market rate of return, providing further incentives for households to save, thereby reducing their debt positions. Equations (12)-(14) show how to price investment projects at different stages of completion. The price of an investment project in its $i$ th quarter of gestation equals the price of a project in the $i$ - 1 quarter of gestation plus $1 / 4$ units of goods. Equation (15) links the cost of producing a unit of capital to the shadow price of installed capital, or Tobin's $Q, q_{t}$. Finally, equation (16) is a pricing condition for physical capital. It equates the revenue from selling one unit of capital today, $q_{t}$, to the discounted value of renting the unit of capital for one period and then selling it, $u_{t+1}+q_{t+1}$, net of depreciation and adjustment costs. 


\subsubsection{Firms}

Output is produced by means of a production function that takes labor services and physical capital as inputs,

$$
y_{t}=F\left(k_{t}, h_{t}\right)
$$

where the function $F$ is assumed to be homogeneous of degree one, increasing in both arguments, and concave. Firms hire labor and capital services from perfectly competitive markets. The production process is subject to a working-capital constraint that requires firms to hold non-interest-bearing assets to finance a fraction of the wage bill each period. Formally, the working-capital constraint takes the form

$$
\kappa_{t} \geq \eta w_{t} h_{t} ; \quad \eta \geq 0
$$

where $\kappa_{t}$ denotes the amount of working capital held by the representative firm in period $t$.

The debt position of the firm, denoted by $d_{t}^{f}$, evolves according to the following expression

$$
d_{t}^{f}=R_{t-1}^{d} d_{t-1}^{f}-F\left(k_{t}, h_{t}\right)+w_{t} h_{t}+u_{t} k_{t}+\pi_{t}-\kappa_{t-1}+\kappa_{t},
$$

where $\pi_{t}$ denotes distributed profits in period $t$, and $R_{t}^{d}$ is the shadow interest rate at which domestic residents borrow and is given by equation (4). As shown by the discussion around equation (4), $R_{t}^{d}$ is indeed the interest rate at which all nonfinancial domestic residents borrow and differs in general from the country interest rate $R_{t}$ due to the presence of debtadjustment costs. Define the firm's total net liabilities at the end of period $t$ as $a_{t}=R_{t}^{d} d_{t}^{f}-\kappa_{t}$. Then, we can rewrite the above expression as

$$
\frac{a_{t}}{R_{t}}=a_{t-1}-F\left(k_{t}, h_{t}\right)+w_{t} h_{t}+u_{t} k_{t}+\pi_{t}+\left(\frac{R_{t}^{d}-1}{R_{t}^{d}}\right) \kappa_{t} .
$$

We will limit attention to the case in which the interest rate is positive at all times. This 
implies that the working-capital constraint will always bind, for otherwise the firm would incur in unnecessary financial costs, which would be suboptimal. So we can use the workingcapital constraint holding with equality to eliminate $\kappa_{t}$ from the above expression to get

$$
\frac{a_{t}}{R_{t}^{d}}=a_{t-1}-F\left(k_{t}, h_{t}\right)+w_{t} h_{t}\left[1+\eta\left(\frac{R_{t}^{d}-1}{R_{t}^{d}}\right)\right]+u_{t} k_{t}+\pi_{t} .
$$

It is clear from this expression that the assumed working-capital constraint increases the unit labor cost by a fraction $\eta\left(R_{t}^{d}-1\right) / R_{t}^{d}$, which is increasing in the interest rate $R_{t}^{d}$.

The firm's objective is to maximize the present discounted value of the stream of profits distributed to its owners, the domestic residents. That is,

$$
\max E_{0} \sum_{t=0}^{\infty} \beta^{t} \frac{\lambda_{t}}{\lambda_{0}} \pi_{t}
$$

We use the household's marginal utility of wealth as the stochastic discount factor because households own domestic firms. Using constraint (18) to eliminate $\pi_{t}$ from the firm's objective function the firm's problem can be stated as choosing processes for $a_{t}, h_{t}$, and $k_{t}$ so as to maximize

$$
E_{0} \sum_{t=0}^{\infty} \beta^{t} \frac{\lambda_{t}}{\lambda_{0}}\left\{\frac{a_{t}}{R_{t}^{d}}-a_{t-1}+F\left(k_{t}, h_{t}\right)-w_{t} h_{t}\left[1+\eta\left(\frac{R_{t}^{d}-1}{R_{t}^{d}}\right)\right]-u_{t} k_{t}\right\}
$$

subject to a no-Ponzi-game borrowing constraint of the form

$$
\lim _{j \rightarrow \infty} E_{t} \frac{a_{t+j}}{\prod_{s=0}^{j} R_{t+s}^{d}} \leq 0
$$

The first-order conditions associated with this problem are (11), (18), the no-Ponzi-game constraint holding with equality, and

$$
F_{h}\left(k_{t}, h_{t}\right)=w_{t}\left[1+\eta\left(\frac{R_{t}^{d}-1}{R_{t}^{d}}\right)\right]
$$




$$
F_{k}\left(k_{t}, h_{t}\right)=u_{t}
$$

It is clear from the first of these two efficiency conditions that the working-capital constraint distorts the labor market by introducing a wedge between the marginal product of labor and the real wage rate. This distortion is larger the larger the opportunity cost of holding working capital, $\left(R_{t}^{d}-1\right) / R_{t}^{d}$, or the higher the intensity of the working capital constraint, $\eta \cdot{ }^{11}$ We also observe that any process $a_{t}$ satisfying equation (18) and the firm's no-Ponzi-game constraint is optimal. We assume that firms start out with no liabilities. Then, an optimal plan consists in holding no liabilities at all times $\left(a_{t}=0\right.$ for all $\left.t \geq 0\right)$, with distributed profits given by

$$
\pi_{t}=F\left(k_{t}, h_{t}\right)-w_{t} h_{t}\left[1+\eta\left(\frac{R_{t}^{d}-1}{R_{t}^{d}}\right)\right]-u_{t} k_{t}
$$

In this case, $d_{t}$ represents the country's net debt position, as well as the amount of debt intermediated by local banks. We also note that the above three equations together with the assumption that the production technology is homogeneous of degree one imply that profits are zero at all times $\left(\pi_{t}=0 \forall t\right)$.

\subsubsection{Driving Forces}

One advantage of our method to assess the plausibility of the identified US-interest-rate shocks and country-spread shocks is that one need not feed into the model shocks other than those whose effects one is interested in studying. This is because we empirically identified not only the distribution of the two shocks we wish to study, but also their contribution to business cycles in emerging economies. In formal terms, we produced empirical estimates of the coefficients associated with $\epsilon_{t}^{r}$ and $\epsilon_{t}^{r u s}$ in the $\mathrm{MA}(\infty)$ representation of the endogenous variables of interest (output, investment, etc.). So using the calibrated model, we can generate the corresponding theoretical objects and compare them. It turns out that up to

\footnotetext{
${ }^{11}$ The precise form taken by this wedge depends on the particular timing assumed in modeling the use of working capital. Here we adopt the shopping-time timing. Alternative assumptions give rise to different specifications of the wedge. For instance, under a cash-in-advance timing the wedge takes the form $1+$ $\eta\left(R_{t}^{d}-1\right)$.
} 
first order, one need not know anything about the distribution of shocks other than $\epsilon_{t}^{r}$ and $\epsilon_{t}^{r u s}$ to construct the coefficients associated with these shocks in the $\mathrm{MA}(\infty)$ representation of endogenous variables implied by the model. We therefore close our model by introducing the law of motion of the country interest rate $R_{t}$. This process is given by our estimate of the bottom equation of the VAR system (1), which is shown in the last columns of table 1. That is, $\hat{R}_{t}$ is given by

$$
\begin{aligned}
\hat{R}_{t} & =0.63 \hat{R}_{t-1}+0.50 \hat{R}_{t}^{u s}+0.35 \hat{R}_{t-1}^{u s}-0.79 \hat{y}_{t}+0.61 \hat{y}_{t-1}+0.11 \hat{\imath}_{t}-0.12 \hat{\imath}_{t-1} \\
& +0.29 t b y_{t}-0.19 t b y_{t-1}+\epsilon_{t}^{r}
\end{aligned}
$$

where $\epsilon^{r}$ is an i.i.d. disturbance with mean zero and standard deviation 0.031. As indicated earlier, the variable $t b y_{t}$ stands for the trade balance-to-GDP ratio and is given by: ${ }^{12}$

$$
t b y_{t}=\frac{y_{t}-c_{t}-i_{t}-\Psi\left(d_{t}\right)}{y_{t}}
$$

Because the process for the country interest rate defined by equation (21) involves the world interest rate $R_{t}^{u s}$, which is assumed to be an exogenous random variable, we must also include this variable's law of motion as part of the set of equations defining the equilibrium behavior of the theoretical model. Accordingly, we stipulate that $R_{t}^{u s}$ follows the $\operatorname{AR}(1)$ process shown in the fourth column of table 1. Specifically,

$$
\hat{R}_{t}^{u s}=0.83 \hat{R}_{t-1}^{u s}+\epsilon_{t}^{r u s}
$$

where $\epsilon_{t}^{r u s}$ is an i.i.d. innovation with mean zero and standard deviation 0.007.

\footnotetext{
${ }^{12}$ In an economy like the one described by our theoretical model, where the debt-adjustment $\operatorname{cost} \Psi\left(d_{t}\right)$ are incurred by households, the national income and product accounts would measure private consumption as $c_{t}+\Psi\left(d_{t}\right)$ and not simply as $c_{t}$. However, because of our maintained assumption that $\Psi^{\prime}(\bar{d})=0$, it follows that both measures of private consumption are identical up to first order.
} 


\subsubsection{Equilibrium, Functional Forms, and Parameter Values}

In equilibrium all households consume identical quantities. Thus, individual consumption equals average consumption across households, or

$$
c_{t}=\tilde{c}_{t} ; \quad t \geq-1 .
$$

An equilibrium is a set of processes $c_{t+1}, \tilde{c}_{t+1}, h_{t+1}, d_{t}, i_{t}, k_{t+1}, s_{i t+1}$ for $i=0,1,2,3, R_{t}$, $R_{t}^{d}, w_{t}, u_{t}, y_{t}, t b y_{t}, \lambda_{t}, q_{t}$, and $\nu_{i t}$ for $i=0,1,2$ satisfying conditions (3)-(17), (19)-(22), and (24), all holding with equality, given $c_{0}, c_{-1}, y_{-1}, i_{-1}, i_{0}, h_{0}$, the processes for the exogenous innovations $\epsilon_{t}^{r u s}$ and $\epsilon_{t}^{r}$, and equation (23) describing the evolution of the world interest rate.

We adopt the following standard functional forms for preferences, technology, capital adjustment costs, and debt adjustment costs,

$$
\begin{gathered}
U(c-\mu \tilde{c}, h)=\frac{\left[c-\mu \tilde{c}-\omega^{-1} h^{\omega}\right]^{1-\gamma}-1}{1-\gamma} \\
F(k, h)=k^{\alpha} h^{1-\alpha} \\
\Phi(x)=x-\frac{\phi}{2}(x-\delta)^{2} ; \quad \phi>0 \\
\Psi(d)=\frac{\psi}{2}(d-\bar{d})^{2}
\end{gathered}
$$

In calibrating the model, the time unit is meant to be one quarter. Following Mendoza (1991), we set $\gamma=2, \omega=1.455$, and $\alpha=.32$. We set the steady-state real interest rate faced by the small economy in international financial markets at 11 percent per year. This value is consistent with an average US interest rate of about 4 percent and an average country premium of 7 percent, both of which are in line with actual data. We set the depreciation rate at 10 percent per year, a standard value in business-cycle studies.

There remain four parameters to assign values to, $\psi, \phi, \eta$, and $\mu$. There is no readily available estimates for these parameters for emerging economies. We therefore proceed to 
estimate them. Our estimation procedure follows Christiano, Eichenbaum, and Evans (2001) and consists of choosing values for the four parameters so as to minimize the distance between the estimated impulse response functions shown in figure 2 and the corresponding impulse responses implied by the model. ${ }^{13}$ In our exercise we consider the first 24 quarters of the impulse response functions of 4 variables (output, investment, the trade balance, and the country interest rate), to 2 shocks (the US-interest-rate shock and the country-spread shock). Thus, we are setting 4 parameter values to match 192 points. Specifically, let $I R^{e}$ denote the $192 \times 1$ vector of estimated impulse response functions and $I R^{m}(\psi, \phi, \eta, \mu)$ the corresponding vector of impulse responses implied by the theoretical model, which is a function of the four parameters we seek to estimate. Then our estimate of $(\psi, \phi, \eta, \mu)$ is given by

$$
\operatorname{argmax}_{\{\psi, \phi, \eta, \mu\}}\left[I R^{e}-I R^{m}(\psi, \phi, \eta, \mu)\right]^{\prime} \Sigma_{I R^{e}}^{-1}\left[I R^{e}-I R^{m}(\psi, \phi, \eta, \mu)\right],
$$

where $\Sigma_{I R^{e}}$ is a $192 \times 192$ diagonal matrix containing the variance of the impulse response function along the diagonal. This matrix penalizes those elements of the estimated impulse response functions associated with large error intervals. The resulting parameter estimates are $\psi=0.00042, \phi=72.8, \eta=1.2$, and $\mu=0.2$. The implied debt adjustment costs are small. For example, a 10 percent increase in $d_{t}$ over its steady-state value $\bar{d}$ maintained over one year has a resource cost of $4 \times 10^{-6}$ percent of annual GDP. On the other hand, capital adjustment costs appear as more significant. For instance, starting in a steadystate situation, a 10 percent increase in investment for one year produces an increase in the capital stock of 0.88 percent. In the absence of capital adjustment costs, the capital stock increases by 0.96 percent. The estimated value of $\eta$ implies that firms maintain a level of working capital equivalent to about 3.6 months of wage payments. Finally, the estimated degree of habit formation is modest compared to the values typically used to explain asset-

\footnotetext{
${ }^{13} \mathrm{~A}$ key difference between the exercise presented here and that in Christiano et al. is that here the estimation procedure requires fitting impulse responses to multiple sources of uncertainty (i.e., countryinterest-rate shocks and world-interest-rate shocks, whereas in Christiano et al. the set of estimated impulse responses used in the estimation procedure are originated by a single shock.
} 
price regularities in closed economies (e.g., Constantinides, 1990). Table 3 summarizes the parameter evaluation.

\subsection{Estimated and Theoretical Impulse Response Functions}

We are now ready to produce the response functions implied by the theoretical model and to compare them to those stemming from the empirical model given by the VAR system (1). Figure 6 depicts the impulse response functions of output, investment, the trade balance-

Figure 6: Theoretical and Estimated Impulse Response Functions
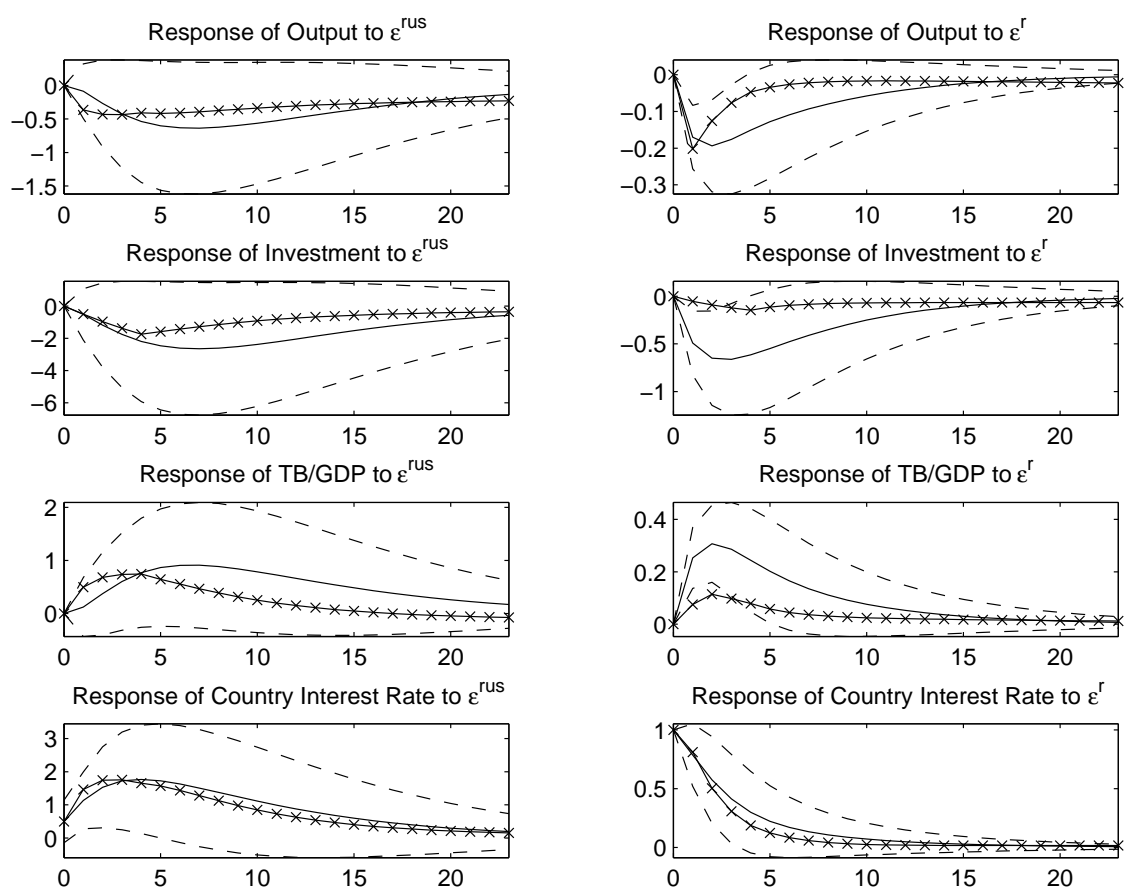

Estimated IR $\quad-\mathrm{x}-\mathrm{x}-$ Model IR

Note: The first column displays impulse responses to a US interest rate shock $\left(\epsilon^{r u s}\right)$, and the second column displays impulse responses to a country-spread shock $\left(\epsilon^{r}\right)$.

to-GDP ratio, and the country interest rate. The left column shows impulse responses to a US-interest-rate shock $\left(\epsilon_{t}^{\text {rus }}\right)$, and the right column shows impulse responses to a countryspread shock $\left(\epsilon_{t}^{r}\right)$. 
The model replicates the data relatively well. All 192 points belonging to the theoretical impulse responses except for three lie inside the estimated two-standard-error bands. Furthermore, the model replicates three key qualitative features of the estimated impulse responses: First, output and investment contract in response to either a US-interest-rate shock or a country-spread shock. Second, the trade balance improves in response to either shock. Third, the country interest rate displays a hump-shaped response to an innovation in the US interest rate. Fourth, the country interest rate displays a monotonic response to a country-spread shock. We therefore conclude that the scheme used to identify the parameters of the VAR system (1) is indeed successful in isolating country-spread shocks and US-interest-rate shocks from the data.

\section{The Endogeneity of Country Spreads: Business Cy- cle Implications}

The estimated process for the country interest rate given in equation (21) implies that the country spread, $\hat{S}_{t}=\hat{R}_{t}-\hat{R}_{t}^{u s}$, moves in response to four types of variable: lagged values of itself (or the autoregressive component, $S_{t-1}$ ), the exogenous country-spread shock (or, in Eichengreen's and Mody's, 1998, terminology, the sentiment component, $\epsilon_{t}^{r}$ ), current and past US interest rates $\left(R_{t}^{u s}\right.$ and $R_{t-1}^{u s}$ ), and current and past values of a set of domestic

endogenous variables $\left(\hat{y}_{t}, \hat{y}_{t-1}, \hat{\imath}_{t}, \hat{\imath}_{t-1}, t \hat{b} y_{t}, t \hat{b} y_{t-1}\right)$. A natural question is to what extent the endogeneity of country spreads contributes to exacerbating aggregate fluctuations in emerging countries.

We address this question by means of two counterfactual exercises. The first exercise aims at gauging the degree to which country spreads amplify the effects of world-interestrate shocks. To this end, we calculate the volatility of endogenous macroeconomic variables due to US-interest-rate shocks in a world where the country spread does not directly depend on the US interest rate. Specifically, we assume that the process for the country interest rate 
is given by

$$
\begin{aligned}
\hat{R}_{t} & =0.63 \hat{R}_{t-1}+\hat{R}_{t}^{u s}-0.63 \hat{R}_{t-1}^{u s}-0.79 \hat{y}_{t}+0.61 \hat{y}_{t-1}+0.11 \hat{\imath}_{t}-0.12 \hat{\imath}_{t-1} \\
& +0.29 t b y_{t}-0.19 t b y_{t-1}+\epsilon_{t}^{r} .
\end{aligned}
$$

This process differs from the one shown in equation (21) only in that the coefficient on the contemporaneous US interest rate is unity and the coefficient on the lagged US interest rate equals -0.63 , which is the negative of the coefficient on the lagged country interest rate. This parameterization has two properties of interest. First, it implies that, given the past value of the country spread, $\hat{S}_{t-1}=\hat{R}_{t-1}-\hat{R}_{t-1}^{u s}$, the current country spread, $S_{t}$, does not directly depend upon current or past values of the US interest rate. Second, the above specification of the country-interest-rate process preserves the dynamics of the model in response to country-spread shocks. The process for the US interest rate is assumed to be unchanged (see equation $(23)$ ). The precise question we wish to answer is: what process for $\hat{R}_{t}$ induces higher volatility in macroeconomic variables in response to US-interest-rate shocks, the one given in equation (21) or the one given in equation (25)? As pointed out earlier in the paper, to address this counterfactual question one cannot simply resort to replacing line five in the VAR system (1) with equation (25) and then recomputing the variance decomposition. For this procedure would be subject to Lucas' (1976) critique on the use of estimated models to evaluate changes in regime. Instead, we appeal to the theoretical model developed in the previous section. The answer stemming from our theoretical model is meaningful for two reasons: First, it is not vulnerable to the Lucas critique, because the theoretical equilibrium is recomputed taking into account the effects of parameter changes on decision rules. Second, we showed earlier in this paper that the theoretical model is capable of capturing the observed macroeconomic dynamics induced by US-interest-rate shocks. This is important because obviously the exercise would be meaningless if conducted within a theoretical framework that fails to provide an adequate account of basic business-cycle stylized facts. 
The result of the exercise is shown in table 4 . We find that when the country spread is assumed not to respond directly to variations in the US interest rate (i.e., under the process for $R_{t}$ given in equation (25)) the standard deviation of output and the trade balance-tooutput ratio explained by US-interest-rate shocks is about two thirds smaller than in the baseline scenario (i.e., when $R_{t}$ follows the process given in equation (21)). This indicates that the aggregate effects of US-interest-rate shocks are strongly amplified by the dependence of country spreads on US interest rates.

A second counterfactual experiment we wish to conduct aims to assess the macroeconomic consequences of the fact that country spreads move in response to changes in domestic variables such as output and the external accounts. To this end, we use our theoretical model to compute the volatility of endogenous domestic variables in an environment where country spreads do not respond to domestic variables. Specifically, we replace the process for the country interest rate given in equation (21) with the process

$$
\hat{R}_{t}=0.63 \hat{R}_{t-1}+0.50 \hat{R}_{t}^{u s}+0.35 \hat{R}_{t-1}^{u s}+\epsilon_{t}^{r} .
$$

Table 4 displays the outcome of this exercise. We find that the equilibrium volatility of output, investment, and the trade balance-to-output ratio explained jointly by US-interestrate shocks and country-spread shocks $\left(\epsilon_{t}^{r u s}\right.$ and $\epsilon_{t}^{r}$ ) falls by about one fourth when the country spread is independent of domestic conditions with respect to the baseline scenario. ${ }^{14}$ Thus, the fact that country spreads respond to the state of business conditions in emerging countries seems to significantly accentuate the degree of aggregate instability in the region.

\footnotetext{
${ }^{14}$ Ideally, this particular exercise should be conducted in an environment with a richer battery of shocks capable of explaining a larger fraction of observed business cycles than that accounted by $\epsilon_{t}^{r u s}$ and $\epsilon_{t}^{r}$ alone.
} 


\section{Conclusion}

Country spreads, the world interest rate, and business conditions in emerging markets are interrelated in complicated ways. Country spreads affect aggregate activity but at the same time respond to domestic macroeconomic fundamentals. The world interest rate has an effect on the country interest rates not only through the familiar no-arbitrage condition but also through country spreads. This paper aims at making a step forward in disentangling these interconnections.

We find that the answer to the question posed in the title of this paper is that country spreads drive business cycles in emerging economies and vice versa. But the effects are not overwhelmingly large. Country spread shocks explain about 12 percent of movements in domestic economic activity, and, in turn, innovations in macroeconomic fundamentals in emerging markets explain abut 12 percent of movements in country spreads.

However, country spreads play a significant role in propagating shocks. For instance, we find that US-interest-rate shocks explain about 20 percent of movements in output. This is a large number. But most of the contribution of US interest rates to business cycles in emerging markets is due to the fact that country spreads respond systematically to variations in this variable. Specifically, if country spreads were independent of the US interest rate, then the variance of emerging countries' output explained by US interest rates would fall by about two thirds. Similarly, a significant fraction of the variability in domestic activity that is explained jointly by world-interest-rate shocks and country-spread shocks is due to the fact that country spreads respond to the state of developing countries' business cycles (as measured by variables such as aggregate output). If country spreads did not respond to variations in emerging countries' domestic fundamentals, then the magnitude of aggregate fluctuations due to US interest-rate shocks and country-spread shocks would fall by around one fourth.

This paper can be extended in a number of directions. First, a key relative price whose behavior any model of emerging market economies should aspire to explain is the real ex- 
change rate. Both the theoretical and empirical models studied here are completely silent on this. Extending the analysis to allow for a nontradable sector is therefore in order.

Perhaps a more important issue to address concerns the microfoundations of countryspread behavior. In this paper the theoretical analysis is limited to the case in which the law of motion of the country spread is given. Nothing is said about why the country premium depends upon variables such as output or the world interest rate. Enriching the theoretical model by providing a more microfounded specification of country spreads is desirable. The improved framework is likely to deal explicitly with issues of debt default, as it seems reasonable to expect that the probability that a country will honor its external obligations is higher the higher are variables such as output, investment, or the trade balance, and the lower is the world interest rate. The existing literature on sovereign debt developed in the 1980s is a natural starting point. But this body of work still remains to be integrated into a dynamic business-cycle framework of the open economy. A recent paper by Arellano (2003) is a step in this direction. An important challenge that the resulting theoretical framework will face has to do with replicating the delayed overshooting in the response of country spreads to world-interest-rate shocks identified in this paper. In effect, our empirical findings suggest that an increase in the world interest rate causes an initial decline in country spreads. After the initial period, the country spread grows rapidly, reaching in a few quarters a level higher than the pre-shock value.

More generally, a central methodological theme of this paper is the combined use of time series analysis and theoretical general equilibrium modeling. Most of the literature extant limits attention to only one of these analytical tools. It is our belief that bringing the prediction of empirical and theoretical models closer together will further enhance our understanding of the forces driving business cycles in the emerging market world. 


\section{Appendix A: An Alternative Scheme for Identifying Country- Spread Shocks}

In this appendix we present an alternative strategy for identifying country-spread shocks. Namely, we assume that innovations to the US interest rate and to country spreads can affect real domestic variables contemporaneously and that innovations to domestic variables affect country spreads with a lag. Formally, the empirical system takes the form

$$
A\left[\begin{array}{c}
\hat{R}_{t}^{u s} \\
\hat{R}_{t} \\
\hat{y}_{t} \\
\hat{\imath}_{t} \\
t b y_{t}
\end{array}\right]=B\left[\begin{array}{c}
\hat{R}_{t-1}^{u s} \\
\hat{R}_{t-1} \\
\hat{y}_{t-1} \\
\hat{\imath}_{t-1} \\
t b y_{t-1}
\end{array}\right]+\left[\begin{array}{c}
\epsilon_{t}^{r u s} \\
\epsilon_{t}^{r} \\
\epsilon_{t}^{y} \\
\epsilon_{t}^{i} \\
\epsilon_{t}^{t b y}
\end{array}\right]
$$

where the matrix $A$ is assumed to be lower triangular. We continue to assume that the US interest rate follows a unit variate $\mathrm{AR}(1)$ process. Table 5 presents the estimation of system (27) using an IV procedure with country specific dummies. Figures 8 and 7 present the associated impulse response functions to a US-interest-rate shock and to a country-spread shock, respectively. Figure 9 depicts the decomposition of the variance of forecasting errors at different horizons.

\section{Appendix B: Data description}

The dataset includes quarterly data for Argentina, Brazil, Ecuador, Mexico, Peru, Philippines, and Venezuela. The sample periods vary across countries. They are : Argentina 1994Q1-2002Q1, Brazil 1994Q3-2002Q1, Ecuador: 1995Q2-2002Q1, Mexico 1994Q1-2001Q1, Peru: 1997Q2-2002Q1, Philippines: 1999Q3-2002Q1, South Africa: 1995Q1-2002Q1. In total, the dataset contains 220 observations. 
Quarterly series for GDP, total consumption, investment and net exports are from the IMF's International Financial Statistics. All of these variables are deflated using the GDP deflator.

In constructing a series for the gross real country interest rate, $R_{t}$, we use the relation $R_{t}=R_{t}^{u s} S_{t}$, where $R_{t}^{u s}$ denotes the gross real world interest rate and $S_{t}$ denotes the gross country spread. The spread is measured using data on spreads from J.P.Morgan's Emerging Markets Bond Index Plus $\left(\mathrm{EMBI}^{+}\right)$. The world interest rate is measured by the interest rate on three-month US treasury bill minus a measure of US expected inflation. Expected inflation is proxied by the average percentage increase in the US GDP deflation over the previous 4 quarters.

$\mathrm{EMBI}^{+}$is a composite index of different US dollar-denominated bonds on four markets: Brady bonds, Eurobonds, U.S. dollar local markets and loans. The spreads are computed as an arithmetic, market-capitalization-weighted average of bond spreads over US treasury bonds of comparable duration. 


\section{References}

Abel, Andrew, "Asset Prices Under Habit Formation and Catching Up With The Joneses," American Economic Review, 80, 1990, pp. 38-42.

Anderson, T. H. and Hsiao, C., "Estimation of Dynamic Models With Error Components," Journal of the American Statistical Association, 76, 1981, 598-606.

Arellano, Cristina, "Default Risk in Emerging Markets," unpublished manuscript, Duke University, September 2003.

Arellano, M. and S. Bond, "Some Tests of Specification for Panel Data: Monte Carlo Evidence and An Application to Employment Equations," Review of Economic Studies, 58, 1991, 277-297.

Boldrin, Michele; Lawrence J. Christiano, and Jonas Fisher, "Asset Pricing Lessons for Modeling Business Cycles," American Economic Review, Vol. 91 (1), 2001, pp. 149166.

Cantor, Richard, and Frank Packer, "Determinants and Impact of Sovereign Credit Ratings," Economic Policy Review, Vol. 2, No. 2, Federal Reserve Bank of New York, October 1996, pp. 37-53.

Christiano, Lawrence J., Martin Eichenbaum, and Charles Evans, "Nominal Rigidities and the Dynamic Effects of a Shock to Monetary Policy," NBER working paper No. 8403, July 2001.

Cline, William R., International Debt Reexamined, Washington, DC: Institute for International Finance, 1995.

Cline, William R. and Kevin S. Barnes, "Spreads and Risk in Emerging Market Lending," Research paper 97-1, Washington, DC, Institute for International Finance, 1997.

Constantinides, George M., "Habit Persistence: A Resolution of the Equity Premium Puzzle," Journal of Political Economy, 1990, 98, 519-543.

Eichengreen, Barry and Ashoka Mody, "What Explains Changing Spreads on EmergingMarket Debt: Fundamentals or Market Sentiment?," NBER Working Paper No. 6408, 
February 1998.

Judson, Ruth A. and Ann L. Owen, "Estimating Dynamic Panel Data Models," A Guide For Macroeconomists, Economic Letters, 65, 1999, pp. 9-15.

Kamin, Steven and Karsten von Kleist, "The Evolution and Determinants of Emerging Market Credit Spreads in the 1990s," BIS Working Paper No. 68, May 1999.

Lucas, R.E., Jr., "Econometric Policy Evaluation: A Critique," Carnegie-Rochester Conference Series on Public Policy, 1976, 1:19-46.

Mendoza, Enrique G., "Real Business Cycles in a Small Open Economy," American Economic Review, 81, 1991, 797-818.

Neumeyer, Pablo A. and Fabrizio Perri, "Business Cycles in Emerging Markets:The Role of Interest Rates," manuscript, New York University, November 2001.

Schmitt-Grohé, Stephanie and Martín Uribe, "Closing Small Open Economy Models," Journal of International Economics, 61, October 2003, pp. 163-185.

Stock, James H. and Mark W. Watson, "Business Cycle Fluctuations in US Macroeconomic Time Series," in John B. Taylor and Michael Woodford, eds., Handbook of Macroeconomics, Amsterdam, The Netherlands: Elsevier Science, 1999, p. 3-64.

Uribe, Martín, "Exchange-Rate-Based Inflation Stabilization: The Initial Real Effects of Credible Plans," Journal of Monetary Economics, June 1997, 39, 197-221.

Uribe, Martín, "The Price-Consumption Puzzle of Currency Pegs," Journal of Monetary Economics 49, April 2002, 533-569. 
Table 1: Parameter Estimates of the VAR system

\begin{tabular}{|c|c|c|c|c|c|}
\hline \multirow{2}{*}{$\begin{array}{c}\text { Independent } \\
\text { Variable }\end{array}$} & \multicolumn{5}{|c|}{ Dependent Variable } \\
\hline & $\hat{y}_{t}$ & $\hat{\imath}_{t}$ & $t b y_{t}$ & $\hat{R}_{t}^{u s}$ & $\hat{R}_{t}$ \\
\hline$\hat{y}_{t}$ & - & $\begin{array}{c}2.739 \\
(10.28)\end{array}$ & $\begin{array}{l}0.295 \\
(2.18)\end{array}$ & - & $\begin{array}{l}-0.791 \\
(-3.72)\end{array}$ \\
\hline$\hat{y}_{t-1}$ & $\begin{array}{c}.282 \\
(2.28)\end{array}$ & $\begin{array}{l}-1.425 \\
(-4.03)\end{array}$ & $\begin{array}{l}-0.032 \\
(-0.25)\end{array}$ & - & $\begin{array}{l}0.617 \\
(2.89)\end{array}$ \\
\hline$\hat{\imath}_{t}$ & - & - & $\begin{array}{l}-0.228 \\
(-6.89)\end{array}$ & - & $\begin{array}{l}0.114 \\
(1.74)\end{array}$ \\
\hline$\hat{\imath}_{t-1}$ & $\begin{array}{l}0.162 \\
(4.56)\end{array}$ & $\begin{array}{l}0.537 \\
(3.64)\end{array}$ & $\begin{array}{l}0.040 \\
(0.77)\end{array}$ & - & $\begin{array}{l}-0.122 \\
(-1.72)\end{array}$ \\
\hline$t b y_{t}$ & - & - & - & - & $\begin{array}{l}0.288 \\
(1.86)\end{array}$ \\
\hline$t b y_{t-1}$ & $\begin{array}{l}0.267 \\
(4.45)\end{array}$ & $\begin{array}{l}-0.308 \\
(-1.30)\end{array}$ & $\begin{array}{l}0.317 \\
(2.46)\end{array}$ & - & $\begin{array}{l}-0.190 \\
(-1.29)\end{array}$ \\
\hline$\hat{R}_{t}^{u s}$ & - & - & - & - & $\begin{array}{l}0.501 \\
(1.55)\end{array}$ \\
\hline$\hat{R}_{t-1}^{u s}$ & $\begin{array}{c}0.0002 \\
(0.00)\end{array}$ & $\begin{array}{l}-0.269 \\
(-0.47)\end{array}$ & $\begin{array}{l}-0.063 \\
(-0.28)\end{array}$ & $\begin{array}{c}.830 \\
(10.89)\end{array}$ & $\begin{array}{l}0.355 \\
(0.73)\end{array}$ \\
\hline$\hat{R}_{t-1}$ & $\begin{array}{l}-0.170 \\
(-3.93)\end{array}$ & $\begin{array}{l}-0.026 \\
(-0.21)\end{array}$ & $\begin{array}{l}0.191 \\
(3.54)\end{array}$ & - & $\begin{array}{l}0.635 \\
(4.25)\end{array}$ \\
\hline$R^{2}$ & 0.724 & 0.842 & 0.765 & 0.664 & 0.619 \\
\hline S.E. & 0.018 & 0.043 & 0.019 & 0.007 & 0.031 \\
\hline No. of obs. & 165 & 165 & 165 & 62 & 160 \\
\hline
\end{tabular}

Notes: $t$-statistics are shown in parenthesis. The system was estimated equation by equation. All equations except for the $\hat{R}_{t}^{u s}$ equation were estimated using instrumental variables with panel data from Argentina, Brazil, Ecuador, Mexico, Peru, Philippines, and South Africa, over the period 1994:1 to 2001:4. The $\hat{R}_{t}^{u s}$ equation was estimated by OLS over the period 1987:1-2002:4.

Table 2: Aggregate Volatility With and Without Feedback of Spreads from Domestic Variables Model

\begin{tabular}{|c|c|c|}
\hline Variable & Feedback & No Feedback \\
\cline { 2 - 3 } & Std. Dev. & Std. Dev. \\
\hline$\hat{y}$ & 3.6450 & 3.0674 \\
$\hat{\imath}$ & 14.1060 & 11.9260 \\
$t b y$ & 4.3846 & 3.5198 \\
$R$ & 6.4955 & 4.7696 \\
\hline
\end{tabular}


Table 3: Parameter Values

\begin{tabular}{|crl|}
\hline \hline Symbol & Value & Description \\
\hline$\beta$ & 0.973 & Subjective discount factor \\
$\gamma$ & 2 & Inverse of intertemporal elasticity of substitution \\
$\mu$ & 0.204 & Habit formation parameter \\
$\omega$ & 1.455 & $1 /(\omega-1)=$ Labor supply elasticity \\
$\alpha$ & 0.32 & capital elasticity of output \\
$\phi$ & 72.8 & Capital adjustment cost parameter \\
$\psi$ & 0.00042 & Debt adjustment cost parameter \\
$\delta$ & 0.025 & Depreciation rate (quarterly) \\
$\eta$ & 1.2 & Fraction of wage bill subject to working-capital constraint \\
$R$ & $2.77 \%$ & Steady-state real country interest rate (quarterly) \\
\hline \hline
\end{tabular}

Table 4: Endogeneity of Country Spreads and Aggregate Instability

\begin{tabular}{|c|c|c|c||c|c|c|}
\hline \multirow{2}{*}{ Variable } & \multicolumn{3}{|c||}{ Std. Dev. due to $\epsilon^{\text {rus }}$} & \multicolumn{3}{c|}{ Std. Dev. due to $\epsilon^{r}$} \\
\cline { 2 - 7 } & $\begin{array}{c}\text { Baseline } \\
\text { Model }\end{array}$ & $\begin{array}{c}S_{t} \text { independent } \\
\text { of } R^{\text {us }}\end{array}$ & $\begin{array}{c}S_{t} \text { independent } \\
\text { of } \hat{y}, \hat{\imath}, \text { or } t b y\end{array}$ & $\begin{array}{c}\text { Baseline } \\
\text { Model }\end{array}$ & $\begin{array}{c}S_{t} \text { independent } \\
\text { of } R^{u s}\end{array}$ & $\begin{array}{c}S_{t} \text { independent } \\
\text { of } \hat{y}, \hat{\imath}, \text { or } t b y\end{array}$ \\
\hline$\hat{y}$ & 1.110 & 0.420 & 0.784 & 0.819 & 0.819 & 0.639 \\
$\hat{\imath}$ & 2.245 & 0.866 & 1.580 & 1.547 & 1.547 & 1.175 \\
$t b y$ & 1.319 & 0.469 & 0.885 & 0.663 & 0.663 & 0.446 \\
$R$ & 3.509 & 1.622 & 2.623 & 4.429 & 4.429 & 3.983 \\
$S$ & 2.515 & 0.347 & 1.640 & 4.429 & 4.429 & 3.983 \\
\hline
\end{tabular}

Note: The variable $S$ denotes the country spread and is defined as $S=R / R^{u s}$. A hat on a variable denotes log-deviation from its non-stochastic steady-state value. 
Table 5: Parameter Estimates of the VAR System when Financial Shocks Affect Real Variables Contemporaneously

\begin{tabular}{|c|c|c|c|c|c|}
\hline \multirow{2}{*}{$\begin{array}{c}\text { Independent } \\
\text { Variable }\end{array}$} & \multicolumn{5}{|c|}{ Dependent Variable } \\
\hline & $\hat{y}_{t}$ & $\hat{\imath}_{t}$ & $t b y_{t}$ & $\hat{R}_{t}^{u s}$ & $\hat{R}_{t}$ \\
\hline$\hat{y}_{t}$ & - & $\begin{array}{l}2.739 \\
(9.79)\end{array}$ & $\begin{array}{l}0.342 \\
(2.47)\end{array}$ & - & - \\
\hline$\hat{y}_{t-1}$ & $\begin{array}{c}.320 \\
(2.79)\end{array}$ & $\begin{array}{l}-1.458 \\
(-3.96)\end{array}$ & $\begin{array}{l}-0.071 \\
(-0.55)\end{array}$ & - & $\begin{array}{l}-0.017 \\
(-0.10)\end{array}$ \\
\hline$\hat{\imath}_{t}$ & - & - & $\begin{array}{l}-0.225 \\
(-6.94)\end{array}$ & - & - \\
\hline$\hat{\imath}_{t-1}$ & $\begin{array}{l}0.135 \\
(4.08)\end{array}$ & $\begin{array}{l}0.545 \\
(3.63)\end{array}$ & $\begin{array}{l}0.037 \\
(0.72)\end{array}$ & - & $\begin{array}{l}-0.073 \\
(-1.45)\end{array}$ \\
\hline$t b y_{t}$ & - & - & - & - & - \\
\hline$t b y_{t-1}$ & $\begin{array}{l}0.235 \\
(4.10)\end{array}$ & $\begin{array}{l}-0.291 \\
(-1.19)\end{array}$ & $\begin{array}{l}0.281 \\
(2.18)\end{array}$ & - & $\begin{array}{l}-0.032 \\
(-0.24)\end{array}$ \\
\hline$\hat{R}_{t}^{u s}$ & $\begin{array}{l}0.287 \\
(1.68)\end{array}$ & $\begin{array}{l}-0.219 \\
(-0.41)\end{array}$ & $\begin{array}{l}0.546 \\
(2.61)\end{array}$ & - & $\begin{array}{c}0.473 \\
(1.41)\end{array}$ \\
\hline$\hat{R}_{t-1}^{u s}$ & $\begin{array}{l}-0.112 \\
(-0.45)\end{array}$ & $\begin{array}{l}-0.083 \\
(-0.11)\end{array}$ & $\begin{array}{l}-0.703 \\
(-2.44)\end{array}$ & $\begin{array}{c}.830 \\
(10.89)\end{array}$ & $\begin{array}{l}0.497 \\
(0.97)\end{array}$ \\
\hline$\hat{R}_{t}$ & $\begin{array}{l}-0.177 \\
(-4.25)\end{array}$ & $\begin{array}{l}0.025 \\
(0.18)\end{array}$ & $\begin{array}{l}0.125 \\
(2.43)\end{array}$ & - & - \\
\hline$\hat{R}_{t-1}$ & $\begin{array}{l}-0.057 \\
(-1.22)\end{array}$ & $\begin{array}{l}-0.039 \\
(-0.28)\end{array}$ & $\begin{array}{l}0.124 \\
(2.14)\end{array}$ & - & $\begin{array}{l}0.580 \\
(3.47)\end{array}$ \\
\hline R-squared & 0.763 & 0.843 & 0.779 & 0.664 & 0.557 \\
\hline S.E. & 0.019 & 0.043 & 0.020 & 0.007 & 0.032 \\
\hline observations & 165 & 165 & 165 & 62 & 160 \\
\hline
\end{tabular}

Notes: $t$-statistics are shown in parenthesis. The system was estimated equation by equation. All equations except for the $\hat{R}_{t}^{u s}$ equation were estimated using instrumental variables with panel data from Argentina, Brazil, Ecuador, Mexico, Peru, Philippines, and South Africa, over the period 1994:1 to 2001:4. The $\hat{R}_{t}^{u s}$ equation was estimated by OLS over the period 1987:1-2002:4. 
Figure 7: Impulse Response To A Country-Spread Shock When Real Variables React Contemporaneously To Financial Innovations
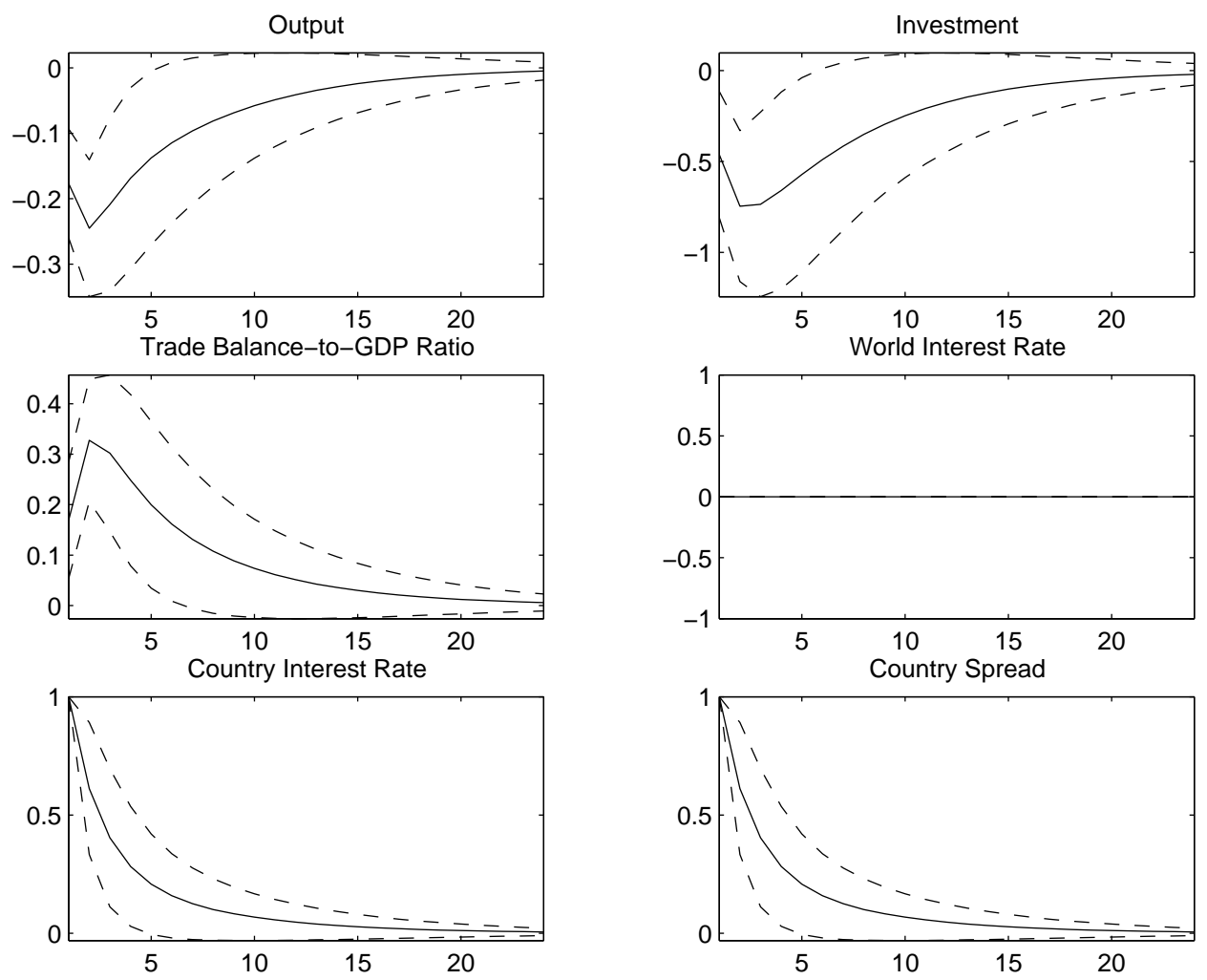

Notes: (1) Solid lines depict the point estimate of the impulse response and broken lines depict two-standard-deviation error bands. (2) The responses of Output and Investment are expressed in percent deviations from their respective $\log$ linear trends. The responses of the Trade Balance-to-GDP ratio, the country interest rate, and the US interest rate are expressed in percentage points. 
Figure 8: Impulse Response To A US-Interest-Rate Shock When Real Variables React Contemporaneously To Financial Innovations
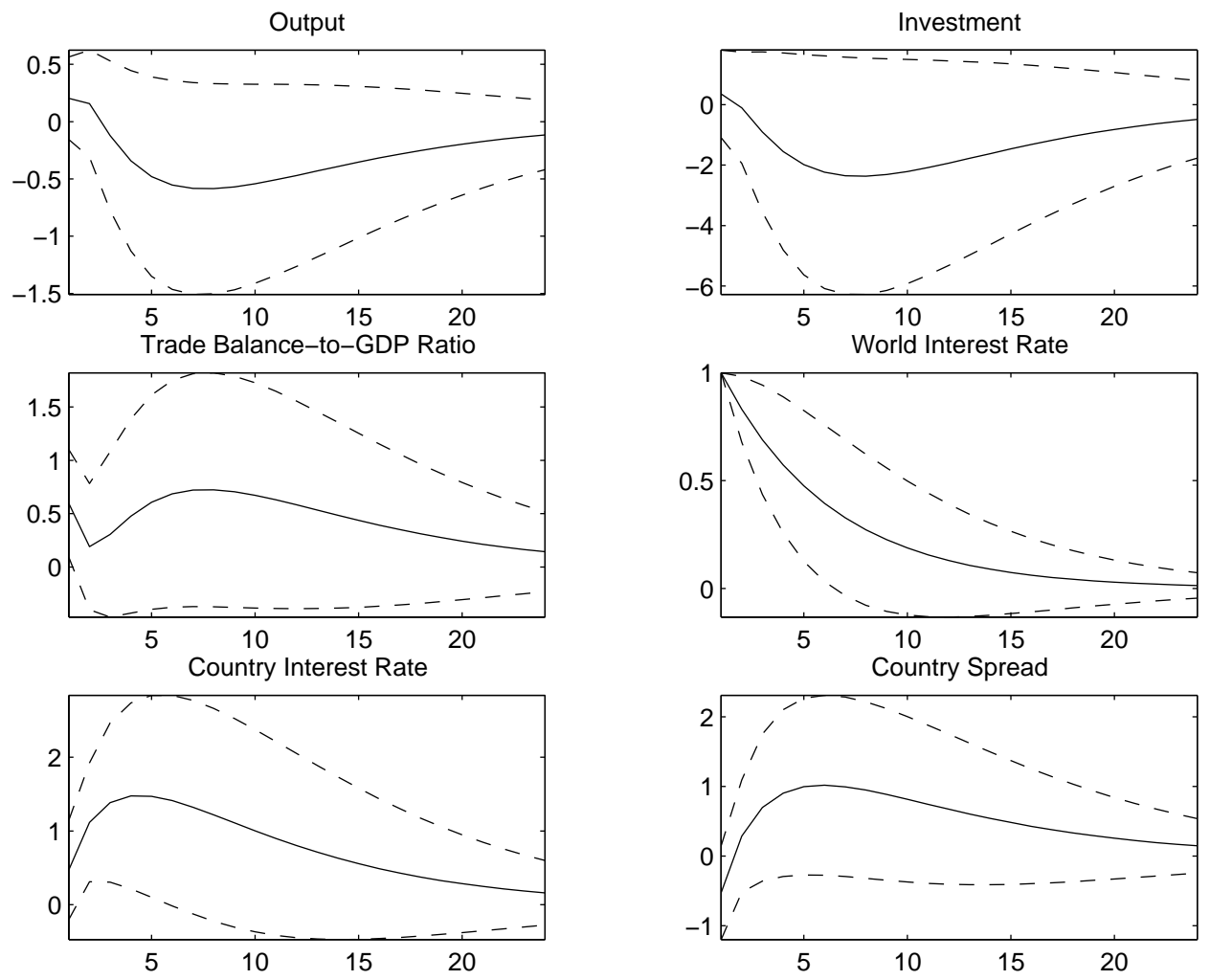

Notes: (1) Solid lines depict the point estimate of the impulse response and broken lines depict two-standard-deviation error bands. (2) The responses of Output and Investment are expressed in percent deviations from their respective log linear trends. The responses of the Trade Balance-to-GDP ratio, the country interest rate, and the US interest rate are expressed in percentage points. 
Figure 9: Fraction of Variance Explained By Innovations in US Interest Rates and Country Spreads At Different Horizons
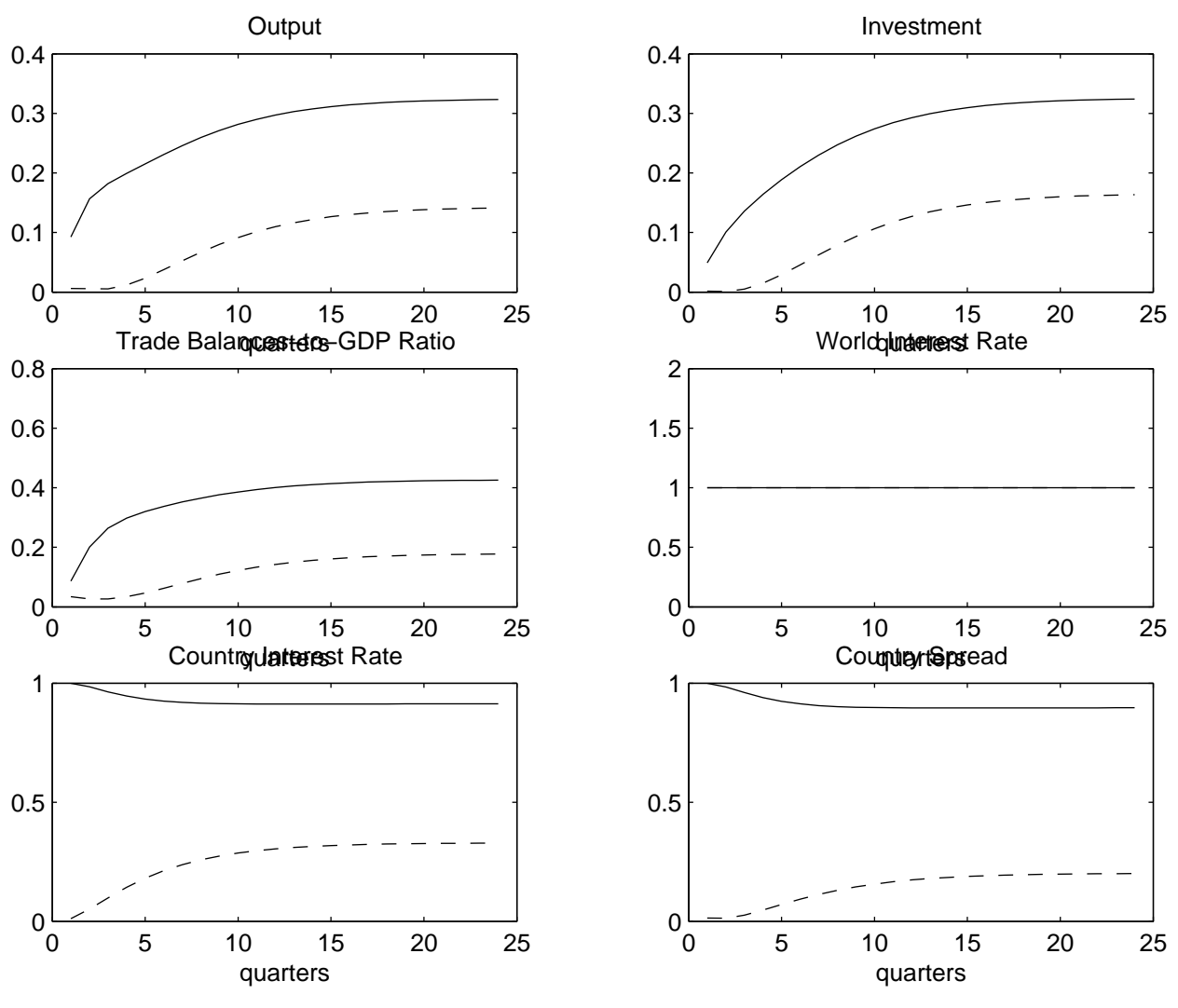

- - $R^{U S}-R^{U S}+R$ 